Schulich School of Law, Dalhousie University

Schulich Law Scholars

Research Papers, Working Papers, Conference

Papers

Faculty Scholarship

3-25-2014

\title{
Of Mitochondria and Men: Why Brain Death is Not the Death of the Human 'Organism as a Whole'
}

Jacquelyn Shaw

Dalhousie University, shawja@dal.ca

Follow this and additional works at: https://digitalcommons.schulichlaw.dal.ca/working_papers

\section{Recommended Citation}

Shaw, Jacquelyn, "Of Mitochondria and Men: Why Brain Death is Not the Death of the Human 'Organism as a Whole"' (2014). Research Papers, Working Papers, Conference Papers. 26.

https://digitalcommons.schulichlaw.dal.ca/working_papers/26

This Working Paper is brought to you for free and open access by the Faculty Scholarship at Schulich Law Scholars. It has been accepted for inclusion in Research Papers, Working Papers, Conference Papers by an authorized administrator of Schulich Law Scholars. For more information, please contact hannah.steeves@dal.ca. 


\title{
OF MitochONDRIA AND MEN: WHY BRAIN DEATH IS NOT THE DEATH OF THE HUMAN "ORGANISM AS A WHOLE"
}

\author{
Jacquelyn Shaw*
}

Death is a phenomenon that resists simple explanation. While the cardiopulmonary criterion of death has been used for centuries, in most nations (including the US and Canada) brain death has also been accepted since 1968 as a second legal criterion, held to be biologically equivalent to bodily death. This equivalence has been argued to derive either from the brain's control over body functions or from the brain's work against entropy, with a dead brain thereby producing a dead body. Subsequently, some have found these claims wanting. An alternative body-centred view, based on the functioning of the body's mitochondria, is that in brain death, only the brain is dead, while the body may not necessarily be. Mitochondria are cellular organelles descended from ancient bacteria, symbiotically providing energy for entropy-resistance and sharing control over life processes. All of death's features - its universality, oxygen-dependence, inevitability, link with aging, irreversibility, and association with disintegration and decay - may be explained as logical side-effects of mitochondrial failure. Yet the role of mitochondria in human life and death has been overlooked for over four decades in the legal and bioethical literature, which has focused instead on processes at the wholeorganism level. Challenges remain however: if brain death and bodily death are not biologically equivalent, this may prove problematic for organ donation's "dead donor rule," which requires organs to be transplanted only from the bodies of dead consenting donors, not from those who are still dying. Nevertheless, brain death could be retained as a legal fiction satisfying the dead donor rule, which would allow its
La mort est un phénomène qui résiste à une explication simple. Bien que le critère de la mort cardiopulmonaire soit utilisé depuis des siècles, dans la plupart des pays (y compris les États-Unis et le Canada) la mort cérébrale est également acceptée depuis 1968 comme critère juridique alternatif, ce critère étant considéré comme biologiquement équivalent à la mort corporelle. On a avancé que cette équivalence dérive soit du contrôle du cerveau sur les fonctions du corps, soit du travail qu'exerce le cerveau pour contrer l'entropie, un cerveau mort produisant ainsi un corps mort. Par la suite, certains ont trouvé des lacunes au niveau de ces revendications. Un autre point de vue centré sur le corps, axé plutôt sur le fonctionnement des mitochondries du corps, considère que lors de la mort cérébrale, seul le cerveau est mort, ce qui n'est pas nécessairement le cas pour le corps. Les mitochondries sont des organites cellulaires, descendantes de bactéries anciennes, fournissant de façon symbiotique de l'énergie servant à combattre l'entropie et participant au contrôle des processus régissant la vie. Toutes les caractéristiques reliées à la mort - son universalité, sa dépendance à l'oxygène, son caractère inévitable, son lien avec le vieillissement, son irréversibilité et son association avec la désintégration et la décadence - peuvent être expliquées en temps qu'effets secondaires logiques de l'échec mitochondrial. Pourtant, le rôle des mitochondries au niveau de la vie humaine et de la mort a été négligé pendant plus de quatre décennies dans la littérature juridique et bioéthique, celleci ayant plutôt mis l'accent sur les processus au niveau de l'organisme entier. Cependant, des questions

\section{* Jacquelyn Shaw, BSc, MSc, LLB, LLM. \\ (C) Jacquelyn Shaw 2014}

Citation: Jacquelyn Shaw, "Of Mitochondria and Men: Why Brain Death is Not the Death of the Human 'Organism as a Whole"” (2014) 7:2 McGill JL \& Health 235.

Référence : Jacquelyn Shaw, «Of Mitochondria and Men: Why Brain Death is Not the Death of the Human 'Organism as a Whole' » (2014) $7: 2$ RD \& santé McGill 235. 
societal benefits to persist. Of fundamental importance is the principle that future patients be adequately informed regarding brain death, in order to ensure legally valid, informed consent for organ donation. subsistent : si la mort cérébrale et la mort du corps ne sont pas biologiquement équivalentes, cela peut s'avérer comme étant problématique pour la « règle du donneur mort », qui exige que les organes à transplanter proviennent uniquement d'organes de donneurs morts et consentants, et non pas de ceux qui sont encore en train de mourir. Néanmoins, la mort cérébrale pourrait être retenue comme une fiction juridique satisfaisant la règle du donneur mort, permettant ainsi à ses avantages sociaux de persister. Le principe voulant que dans le futur les patients soient informés de manière adéquate concernant la mort cérébrale est d'une importance fondamentale, et ceci afin d'assurer le consentement juridiquement valable et éclairé au don d'organes.

Introduction

I. Human Death: Conceptualizing an Ancient Enigma

II. Brain Death and Death of the Body: The Search for a Defensible Biological Rationale

A. The Brain as "Master Regulator" of the Body's Functions

B. The Neurological "Self-Preserving Work" of the Organism as a Whole

C. Death: A Mitochondrial Account

1. The importance of mitochondria in cellular life

2. Mitochondria in the life of somatically integrated organisms

3. Mitochondria and the mystery of life's oxygen-dependence

4. Mitochondria in the pathways of cell death

5. Mitochondria in the aging and death of the organism as a whole 283

III.Mitochondrial Viability in the Brain-Dead Body

IV. Addressing the Lack of Equivalence between Brain Death and Death of the Human "Organism as a Whole" 


\section{Introduction}

Since ancient times, death has been a phenomenon surrounded by mystery. Immediately before and after death, the same physical matter appears present, while after death, something intangible is permanently gone. ${ }^{1}$ Like blind men describing an elephant, ${ }^{2}$ scholars seeking to define death have unsuccessfully attempted piecemeal explanations of death's strange commonalities in humans and other animals: its universality; its seeming inevitability, irreversibility, and link with aging; and its oxygen-dependence and temporal association with cardiopulmonary cessation, loss of whole-body integration, and decay.

For centuries, human death was diagnosed solely via the cardiopulmonary criterion: the interrelated cessation of breathing and heartbeat. Then, in 1968, Canada and other nations also embraced "brain death" as a second, legally equivalent criterion. Over four decades later, brain death is a familiar

${ }^{1}$ The search for a definition of death is complicated by the lack of an accepted definition of life. Some resort to religious arguments involving an incorporeal spirit or vital essence. Seeking a more scientific source within the component matter of living things, David Suzuki and Wayne Grady speculate that life is a synergy among inanimate components rather than being due to any one component: "Life itself is ... testimony that wholes are greater than the sum of their parts ... [I]f there is no vital force or spirit present in the ultimate particles of matter, then life must result from the collective interaction of nonliving parts, a synergy that produces such emergent properties as respiration, digestion, and reproduction": David Suzuki \& Wayne Grady, Tree: A Life Story (Toronto: Greystone Books, 2004) at 52. This paper explores in detail the idea of synergy within living things.

2 "A certain raja presented an elephant to a group of blind men ... When asked what the elephant was, the man presented with the head answered, 'Sire, an elephant is like a pot.' He who had observed the ear replied, 'An elephant is like a winnowing basket.' Presented with a tusk, another said it was a ploughshare ... [Q]uarrelling, each to his view they cling. Such folk see only one side of a thing": Parable of the Blind Men and the Elephant, Khuddaka Nikaya 3: Udana 68-69, this version cited in Caitlin O'Connell, The Elephant's Secret Sense: The Hidden Life of the Wild Herds of Africa (Chicago: University of Chicago Press, 2007) at 183. Coincidentally, another author has noted the similarity between this parable and the scholarly debate surrounding death, but has adopted a different philosophical position; see D Alan Shewmon, "Constructing the Death Elephant: A Synthetic Paradigm Shift for the Definition, Criteria, and Tests for Death" (2010) 35:3 J Med Philos 256 at 257, 264-65 [Shewmon, "Elephant"]. 
concept in Canada and other developed nations. Worldwide, most countries apply the "whole-brain" version of the neurological criterion of death, wherein the entire brain (including the brain stem) has permanently ceased functioning; Canada, however, shifted to a brain stem criterion in $2003,{ }^{3}$ and some suggest that the US may one day follow. ${ }^{4}$ Overall, many consider the societal acceptability of the concept of brain death settled. ${ }^{5}$ Yet others disagree. $^{6}$

${ }^{3}$ From 1968 to 2003, Canada employed the "whole-brain" criterion, like the US, Australia, and many other nations. However, the issuance of the 2003 Canadian Council for Donation and Transplantation (CCDT) brain death guidelines marked a shift to the brain stem criterion that the United Kingdom adopted in the 1970s. The CCDT authors stated, "In Canada we accept the clinical criteria for brain death (essentially brain stem death)" and "All of the clinical criteria for brain death are met with irreversible, total destruction of the brain stem. This is confirmed in the recently adopted Canadian [CCDT] guidelines for the neurological determination of death": G Bryan Young et al, "Brief Review: The Role of Ancillary Tests in the Neurological Determination of Death" (2006) 53:6 Can J Anaesth 620 at 620-21 [emphasis added]. However, use of the new criterion has been non-uniform across Canada; see Wayne Kondro, "Fragmented Organ Donation Programs Hinder Progress" (2006) 175:9 Can Med Assoc J 1043 at 1044.

${ }^{4}$ While the 2009 US examination of the defensibility of brain death reaffirmed wholebrain death, some interpret its wording as preparing for a future US move to brain stem death: see D Alan Shewmon, "Brain Death: Can It Be Resuscitated?" (2009) 39:2 Hastings Cent Rep 18 at 20, 22 [Shewmon, "Brain Death Resuscitated"].

5 "[T] he whole-brain concept of death now has reached a degree of societal acceptance rare for bioethical issues, one that has been sufficient for nearly all jurisdictions in the US and many Western countries ... Indeed, some bioethicists no longer regard brain death as a seriously controversial issue and have grown bored with its persisting discussion": James L Bernat, "A Defense of the Whole-Brain Concept of Death" (1998) 28:2 Hastings Cent Rep 14 at 14 [Bernat, "Whole-Brain Defense"].

${ }^{6}$ See e.g. Paul A Byrne \& Walt F Weaver, “Brain Death' Is Not Death” in Calixto Machado \& D Alan Shewmon, eds, Advances in Experimental Medicine and Biology, vol 550: Brain Death and Disorders of Consciousness (New York: Springer Science+Business Media, 2004) 43; Ari Robin Joffe, "The Neurological Determination of Death: What Does It Really Mean?” (2007) 23:2 Issues L \& Med 119; D Alan Shewmon, “'Brainstem Death,' 'Brain Death' and Death: A Critical Reevaluation of the Purported Equivalence" (1998) 14:2 Issues L \& Med 125 [Shewmon, "Critical Re-evaluation"]. 
As one of the few certainties in human life, the declaration of death triggers important legal decisions regarding life support, organ harvesting (with consent), estate settling, care of surviving minor offspring, and culturally appropriate disposal of remains. These decisions are justified by the societal understanding of biological death as irreversible. The biological justification for accepting cardiopulmonary silence as legal death seems straightforward, since the loss of breathing and/or heartbeat has long been observed to generally become irreversible after a period of time. Yet the biological rationale for brain death as a legal criterion of death is less clear. Thus, neurological death may benefit from a new perspective, more consistent with recent scientific evidence.

\section{Human Death: Conceptualizing an Ancient Enigma}

Among those who theorize about life and death, a diversity of philosophical viewpoints exists. There are, for instance, those who argue (as this paper does) that the major locus of life and death in human beings is the physical organism or body, with the human "mind" (and perhaps also "soul") being mainly an epiphenomenon of one particular body part and its functions, i.e., the brain. In contrast, others maintain that, during life, human beings consist of two components: a body and a mind (where the latter is not simply an epiphenomenon of brain functions), possibly in addition to a soul that is linked to either the body or the mind. ${ }^{7}$ These various perspectives on human life will obviously entail very different interpretations of what death is. As some authors have noted, these different initial philosophies colour interpretations of empirical observations about life and death in ways that tend to confirm the holder's original philosophical position. ${ }^{8}$ Strong opposition and heated debate result.

Two competing conceptualizations of human death have historically dominated scholarly debate. One is the "personhood" camp, which more greatly values the contribution of mental changes in death, and which argues that death represents loss of a human "person" with unique mental attributes (i.e., a mind). The second is the "body-centred" camp, which maintains that death represents the physical end of the human "organism." Despite fierce, protracted debate, there are no signs of agreement or compromise likely be-

\footnotetext{
${ }^{7}$ Shewmon, "Elephant", supra note 2 at 265.

${ }^{8}$ Ibid at 264-65.
} 
tween these two opposing camps $;{ }^{9}$ no thought experiments resolve the issue and, as noted, each camp may interpret its empirical observations of death as confirming its original position.

Accordingly, a more detailed elucidation of the personhood perspective on death seems especially useful here. The personhood view argues that a human being possesses mental traits - a unique constellation of mental attributes, skills, memories, relationships, etc. Mental personhood is distinct from "legal personhood" (the legal capacity to hold rights), which all living humans are held to possess after birth. Some scholars, such as Edward Bartlett and Stuart Youngner, have argued that the loss of characteristics typically associated with mental personhood - i.e., consciousness and cognition should be deemed the key event triggering a declaration of legal death. ${ }^{10}$ This would require employing a "neocortical" (or "higher-brain") criterion of brain death, rather than the whole-brain neurological criterion that is currently the most common choice worldwide. However, many view a neocortical death criterion as too radical in relation to societal values; ${ }^{11}$ notably, no na-

${ }^{9}$ Ibid at 263-64 (" $[\mathrm{t}]$ he question ... whether human personhood is actually separable from human organismhood ... has been debated intensely by philosophers for a very long time without any signs of rapprochement").

${ }^{10}$ Bartlett and Youngner argue, "Death is not the loss of something ... [I]t is the loss of someone. Because a human being is a person, the irreversible destruction of the cortex - i.e., the center of consciousness and cognition - constitutes death"; therefore, they conclude, "We believe that only the higher brain functions, consciousness and cognition, define the life and death of a human being": Edward T Bartlett \& Stuart J Youngner, "Human Death and the Destruction of the Neocortex" in Richard M Zaner, ed, Death: Beyond Whole-Brain Criteria (Boston: Kluwer Academic Publishers, 1988) 199 at 211, 215.

${ }^{11}$ See e.g. James L Bernat, Charles M Culver \& Bernard Gert, "On the Definition and Criterion of Death" (1981) 94 Ann Intern Med 389 ("[t]o bury such patients while they breathe and have a heartbeat, most would view as at least esthetically unacceptable" at 391). This still appears as true today as in 1981, as indicated by the 2008 US President's Council on Bioethics, which stated, "Only when all would agree that the body is ready for burial can that body, with confidence, be described as dead," and, in discussing the potential to harvest organs from patients in a persistent vegetative state, "[If] the Kantian prohibition against treating living human beings merely as means and not also as ends ... is worth preserving, ... we would do better to restrict donation-eligibility to patients who have died, as determined by clinical tests for ... "whole brain death": President's Council on Bioethics, Controversies in the Determination of Death: A White Paper by the President's 
tion has adopted this criterion to date. A neocortical criterion also seems inconsistent with what many ordinary, untrained members of the public may mean by "death," which this paper takes as a valuable perspective. What ordinary members of the public think death involves has relevance to their provision of informed consent (e.g., for processes such as organ donation), so it is important to know if medical perspectives conflict with that view. This "ordinary person" perspective, at least in part, seems to involve the physical death of the body, as explained in Part IV, below.

Neurologist James Bernat, a leading architect of the whole-brain death concept, has argued, "[W]e refer to ... the same phenomenon when we describe the death of a dog [and] ... the death of a human being." 12 This is the view that the ordinary "man or woman in the street" probably holds regarding death, based on his or her empirical observations. Such "lay" observation suggests that death (a) is irreversible, (b) involves a cessation of all of the observable physical, as well as mental, functions of a human being or other organism, (c) is often associated with aging or (d) with the interruption of oxygen, and (e) closely precedes widespread tissue destruction and the onset of bodily decay. Some argue that death involves a discrete point in time, while others believe it is a process occurring over a period of time. ${ }^{13}$

Empirically too, as Bernat suggests, death is a phenomenon similarly affecting not only humans but all known animal and other life. No scientific evidence suggests that death is a different process having different evolutionary origins in non-human vertebrate animals, such as dogs, than in people. Consistent with the Darwinian view of human beings as animals, death appears to be equivalent and homologous ${ }^{14}$ in humans and non-human vertebrates. This being widely accepted, the body seems a key part of explaining death in the commonly understood sense. Thus, if death is, as Bernat argues,

Council on Bioethics, December 2008, online: PCB Archive $<\mathrm{http} / / /$ bioethics.georgetown.edu/pcbe/reports/death/index.html $>$ at 53,72 [President's Council].

${ }^{12}$ Bernat, "Whole-Brain Defense", supra note 5 at 15.

${ }^{13}$ Ibid at $15-16$.

14 "Homologous" characteristics are those that trace from common ancestry, in contrast to superficially similar traits created through convergent evolution from different ancestral origins. 
"the same phenomenon" in humans and non-human animals, then it seemingly must involve the body and not just mental personhood; this is because loss of personhood is a criterion that cannot be applied to non-human vertebrates without first ascribing mental personhood to them - an approach which has not found general acceptance. To allow for the observed "trans-species universality," death - whether of humans or of animals - must involve destruction of the body, rather than of the mental person. ${ }^{15}$

However, while this paper accepts the above view - that death is "univocal," i.e., the same process in humans and other (vertebrate ${ }^{16}$ ) animals - this view is not universally accepted. Some philosophers, adopting a personhood view of human death, suggest that death should be seen as based on mental rather than body-related changes and therefore as a different process in humans (and "higher" animals) compared with "less advanced" animals. ${ }^{17}$ As noted, this paper accepts death as a principally biophysical process exhibiting trans-species universality, based on a common explanation in all vertebrates, and it will not further discuss the view that death may differ in humans and non-human organisms.

A second reason to reject the view that death involves simply the loss of mental personhood characteristics is that we would also need to explain by what mechanism mental personhood (and its disappearance) give rise to, or are tightly linked with, an organism's physical life functions (and their permanent loss in death). One illustration of a mental personhood approach to life and death is the view of "transhumanist" author and information technology expert Ray Kurzweil. He argues, based on his observations of a "dynam-

15 See Jocelyn Downie, "Brain Death and Brain Life: Rethinking the Connection" (1990) 4:3 Bioethics 216 at 223.

${ }^{16}$ While the present author argues that the same biophysical death mechanism operates in all animals, one cannot argue with complete accuracy that "death is the same process" in invertebrate animals as in humans and vertebrates. This is because invertebrates (but not vertebrates) can reproduce asexually, by subdivision of the body of a "parent" organism into new "offspring." Thus, a significant portion of the original "parent" invertebrate's body may survive and continue functioning in "daughter" organisms, even when the parent is destroyed, potentially adding a dimension to the invertebrate death process that has no counterpart in vertebrates.

${ }^{17}$ See e.g. John P Lizza, Persons, Humanity and the Definition of Death (Baltimore: Johns Hopkins University Press, 2006) at 18-19. 
ic equilibrium" existing among living and dying cells in a healthy human body, that human beings are "energy patterns," much like computer programs or files, in which some elements (i.e., cells) are continually replaced while the overall life of the program or file (i.e., the human being) persists over time.$^{18}$ Kurzweil's argument resembles and may be based upon the earlier claim of cybernetics founder Norbert Wiener:

Our tissues change as we live: the food we eat and the air we breathe become flesh of our flesh and bone of our bone, and the momentary elements of our flesh and bone pass out of our body every day with our excreta.... We are not stuff that abides but patterns that perpetuate themselves. ${ }^{19}$

Kurzweil and other transhumanists anticipate that each human "file" - i.e., the information content of consciousness comprising each individual human "pattern" - will one day be immortalized permanently in silico, making death a thing of the past, as we physically and mentally merge with computers. ${ }^{20}$ Nevertheless, neither Kurzweil nor Wiener offers a theory regarding how our bodies, housing these mental energy "patterns," persist physically, nor why these physical bodies cease to function at some point and cannot seemingly be repaired by any known means.

As this paper demonstrates, however, there is a plausible scientific mechanism that can explain these human mental patterns' persistence within physical bodies for a finite period, followed by their eventual, irreversible disappearance. For the reasons noted, this paper will accept the view of death as primarily a physical process, involving the body (and the mind as derived from that body). In this view, then, death of the mind is a natural consequence of death of the body. This paper will not further debate the view of

${ }^{18}$ Ray Kurzweil, The Singularity Is Near: When Humans Transcend Biology (New York: Penguin Books, 2005) at 325.

${ }^{19}$ Norbert Wiener, The Human Use of Human Beings: Cybernetics and Society, $2 \mathrm{~d}$ ed (New York: Doubleday, 1954) at 96 [emphasis added].

${ }^{20}$ See DI Dubrovsky, “Cybernetic Immortality. Fantasy or Scientific Problem?”, 2045 Initiative (2 November 2012), online: 2045 Initiative <http://2045.com/articles/ 30810.html>; see also Lauren O'Neil, "Human immortality could be possible by 2045, say Russian scientists", CBC News (31 July 2012), online: CBC <www.cbc.ca/newsblogs/yourcommunity/2012/07/human-immortality-could-bepossible-by-2045-say-russian-scientists.html>. 
death as based on loss of mental personhood, beyond acknowledging that a new body-centred explanation for death is unlikely to convince those who take loss of personhood to be the key event in death.

\section{Brain Death and Death of the Body: The Search for a Defensible Biological Rationale}

If we accept, as this paper does, that death is a physical process, such that the death of a dog and the death of a human being are based on the same physical, biological phenomenon, and if brain death and bodily death are equivalent, then how can we explain the various aspects of the "elephant" for example, the body's permanent loss of functioning, the irreversibility of this loss, and death's temporal association with disintegration and decay? Several theories have attempted to account for this over the decades in which brain death has been employed as a criterion for legal death.

\section{A. The Brain as "Master Regulator" of the Body's Functions}

According to the view articulated by the 1981 President's Commission for the Study of Ethical Problems in Medicine and Biomedical and Behavioral Research, the first of two US bioethics commissions justifying the use of whole-brain death as a legal death criterion, the functioning brain in a human being (or non-human vertebrate) serves a "master regulatory" role, directing and coordinating all functions of the entire body. ${ }^{21}$ In forming its conclusion, the Commission argued that the functioning whole brain makes possible, as well as governs, a kind of synergistic "pseudo-entity" that is more than the sum of its component cells, tissues, and organ systems. ${ }^{22}$ The

${ }^{21}$ President's Commission for the Study of Ethical Problems in Medicine and Biomedical and Behavioral Research, Defining Death: Medical, Legal and Ethical Issues in the Determination of Death (Washington, DC: President's Commission for the Study of Ethical Problems in Medicine and Biomedical and Behavioral Research, 1981) at 32, 34-35 [President's Commission]. The President's Commission report was, in turn, founded on the analysis of death by Bernat, Culver \& Gert, supra note 11 .

22 The President's Commission did not actually employ the term "pseudo-entity" in describing the "organism as a whole" that it saw as being formed by the integration and coordination functions of the whole brain. Applying a whole-brain formulation, it stated that "life consists of the coordinated functioning of the various bodily 
Commission termed this entity "the organism as a whole." 23 Notably, the component cells, tissues, and organ systems of the organism as a whole display a characteristic degree of "somatic integration" by behaving cooperatively to produce "emergent functions" 24 - functions seen only at the level of the organism (e.g., whole-body movement and consciousness). As Bernat clarifies, the organism as a whole comprises a "set of functions that are greater than the mere sum of the organism's parts," ${ }^{25}$ due to synergistic

systems, in which process the whole brain plays a crucial role" (President's Commission, supra note 21 at 35 ) and that:

[t] he functioning of many organs ... and their integration are "vital" to individual health in the sense that if any one ceases and that function is not restored or artificially [replaced], the organism as a whole cannot long survive. All elements in the system are mutually interdependent, so that the loss of any part leads to the breakdown of the whole and, eventually, to the cessation of functions in every part [ibid at 32].

Thus, "the brain [is given] primacy not merely as the sponsor of consciousness ... but also as the complex organizer and regulator of bodily functions.... Only the brain can direct the entire organism": ibid at 34. Further, "the centrality accorded the brain reflects both its overarching role as 'regulator' or 'integrator' of other bodily systems and the immediate and devastating consequences of its loss for the organism as a whole": ibid at 35. Accordingly, the Commission concluded that the whole-brain concept of death merely "reinforce[s] the concept of death as a single phenomenon - the collapse of psycho-physical integrity.... Although absence of breathing and heartbeat may often have been spoken of as 'defining' death ... these [are] merely evidence for the disintegration of the organism as a whole": ibid at 58 .

23 The "organism as a whole" concept has been credited to Jacques Loeb: see James L Bernat, "The Whole-Brain Concept of Death Remains Optimum Public Policy" (2006) 34:1 JL Med \& Ethics 35 at 38 [Bernat, "Whole-Brain Optimum"].

${ }^{24}$ An "emergent function" has been defined as "a property of a whole that is not possessed by any of its component parts, and that cannot be reduced to one or more of its component parts": ibid. Or alternatively: "A property ... is defined as "emergent' if it derives from the mutual interaction of the parts": Shewmon, "Critical Reevaluation", supra note 6 at 137. See also Francis Crick, The Astonishing Hypothesis: The Scientific Search for the Soul (New York: Charles Scribner's Sons, 1994) ("[w]hile the whole may not be the simple sum of the separate parts," its properties can be predicted "from the nature and behaviour of the parts plus the knowledge of how all these parts interact" at 11 [emphasis in original]).

${ }^{25}$ Bernat, "Whole-Brain Optimum", supra note 23 at 38. 
interactions among those parts. Somatically integrated living organisms do seem to behave as if the component tissues together pursue the common purpose of one "individual."

Justifying its acceptance of the whole-brain criterion of death, the President's Commission claimed that within the organism as a whole, three organs - the heart, lungs, and brain - form a very close relationship. It held that these three organs form a "triangle of interrelated systems with the brain at its apex, ${ }^{26}$ suggesting the brain's greater importance as the supposed regulatory controller of all body functions. This relationship between the three organs was said to be so close that permanent loss of any one "corner" of the triangle would quickly destroy the other two corners. ${ }^{27}$ In the Commission's view, emergent life functions of living organisms are produced by synergistic co-operation and integration among specialized body tissues, which in turn originate with the brain's master role:

One characteristic of living things which is absent in the dead is the body's capacity to organize and regulate itself. In animals, the neural apparatus is the dominant locus of these functions. ${ }^{28}$

And:

[In humans and higher animals] the functioning of the whole brain [is understood] as the hallmark of life because the brain is the regulator of the body's integration. ${ }^{29}$

Therefore:

[D]eath is that moment at which the body's physiological system ceases to constitute an integrated whole. Even if life continues in individual cells or organs, life of the organism as a whole requires complex integration, and without the latter, a person cannot properly be regarded as alive. ${ }^{30}$

\footnotetext{
${ }^{26}$ President's Commission, supra note 21 at 33 [emphasis added].

${ }^{27}$ Ibid at 33.

${ }^{28} \mathrm{Ibid}$ at 32 [emphasis added].

${ }^{29}$ Ibid [emphasis added].

${ }^{30}$ Ibid at 33 [emphasis added].
} 
This loss of bodily integration with brain death was argued to be rapid. After brain death, it was claimed, the body quickly ceases operating as a functioning, integrated whole, and its systems become uncontrolled and uncoordinated:

[T] he brain is necessary for the functioning of the organism as a whole. It integrates, generates, interrelates, and controls complex bodily activities. A patient on a ventilator with a totally destroyed brain is merely a group of artificially maintained subsystems since the organism as a whole has ceased to function. ${ }^{31}$

Associated with this view was the argument that, despite ventilator support, cardiopulmonary death will occur reliably and spontaneously soon after brain death. As the President's Commission stated, "[e]ven with extraordinary medical care, these [somatic] functions cannot be sustained indefinitely - typically no longer than several days." 32

${ }^{31}$ Bernat, Culver \& Gert, supra note 11 at 391 [emphasis added].

32 President's Commission, supra note 21, cited in Shewmon, "Critical Re-evaluation", supra note 6 at 134 [emphasis added]. See also C Pallis, "Whole-Brain Death Reconsidered - Physiological Facts and Philosophy" (1983) 9:1 J Med Ethics 32 (" $[\mathrm{t}]$ he reasons why the heart stops within a short while when the brain-stemmediated baroceptor reflexes are disrupted, and when the vasometer centre is destroyed, are complex but the empirical fact is established beyond all doubt" at 36 [emphasis added]). The President's Commission reported that "the heart usually stops beating within two to ten days": supra note 21 at 17. It further argued that "the centrality accorded the brain reflects both its overarching role as 'regulator' or 'integrator' of other bodily systems and the immediate and devastating consequences of its loss for the organism as a whole": ibid at 35 [emphasis added]. A 1977 study claimed $99 \%$ of subjects "died within a week with evidence of a dead brain," but recommended a larger study: National Institutes of Neurological and Communicative Disorders and Stroke, "An Appraisal of the Criteria of Cerebral Death: A Summary: A Collaborative Study" (1977) 237:10 JAMA 982 at 984-85 [NINCDS]. Shewmon has argued that this conclusion was based on a very limited patient sample (503 patients) with a sizeable (1\%) error rate; to lower these error rates to a more acceptable $0.001 \%$ (given the high stakes of declaring death), a sample of over one million patients would be needed, a study that has yet to be done: D Alan Shewmon, "The Probability of Inevitability: The Inherent Impossibility of Validating Criteria for Brain Death or 'Irreversibility' Through Clinical Studies" (1987) 6:5 Stat Med 535 at 548. While 503 instances of support for a claimed biological rule may at first blush appear more substantial to some than a 
On the positive side, the master regulator view provided a rationale for organs to be harvested without violation of the "dead donor rule" ("DDR"), an ethical rule that requires that organ harvesting not be the proximate cause of a donor's death. Because, under the master regulator view, the body of a brain-dead patient ostensibly is - or shortly will be - dead too, organ harvesting does not violate the DDR. Undoubtedly, many organ recipients have benefited greatly from the donor organs made available by the master regulator perspective. However, while it is a positive result for those organ recipients, this benefit may be outweighed by its costs in terms of the integrity of information provided to patients. In the years after the President's Commission, the master regulatory theory was demonstrated to suffer from a number of defects, especially as regards its account of the integrated "organism as a whole," wherein emergent body functions were argued to originate from brain regulatory function.

First, to date, no precise, brain-based mechanism has ever been elucidated for the claimed onset of cardiopulmonary death within days after brain death. Some researchers, such as Paul Byrne and Walt Weaver, argue that no neurological mechanism exists to allow brain-mediated integration of all body systems: "[T] he brain as a whole has no physiologically identifiable ... functions that could rightly be called the "life-giving ... functions." 33 Neurologist Alan Shewmon has argued that only three anatomical means exist by which the brain could coordinate bodily functions: the spinal cord, vagus nerve, and pituitary. Based on these, he concludes that if the master regulator view were correct, the effect of brain death (which often spares pituitary function) on bodily integration would be clinically identical to the combined effects of severance of the cervical spinal cord (cutting off the body from any brain input) and pharmacologically-induced ablation of the vagus nerve function. ${ }^{34}$ Yet spinal cord severance is not a condition in which the body is

175-patient study disproving that rule, in fact, these numbers must be considered in light of the different weight to be given to instances of proof and disproof, the latter being weighted more heavily in scientific research, since they indicate problems with a claimed rule. In addition, the 503-patient study had a high reported error rate. This tends to corroborate (not contradict) the 175-patient study's conclusion of possible unreliability in the claimed rule that brain death leads immediately or rapidly to cardiopulmonary death.

${ }^{33}$ Byrne \& Weaver, supra note 6 at 44.

${ }^{34}$ Shewmon, "Critical Re-evaluation”, supra note 6 at 140-41. Such ablation may be accomplished with atropine: see Young et al, supra note 3 at 625. 
considered "dead," suggesting that the master regulator view is incorrect. Thus, a mechanism for the rapid cessation of heartbeat in brain death remains lacking.

A second flaw is that the theory that brain function produces emergent functions of the "organism as a whole" cannot account for cases such as hypothermia or barbiturate intoxication, where total brain malfunction occurs even for several days, but is accompanied by only a reversible loss of the emergent life properties ${ }^{35}$ of the "organism as a whole." In such circumstances, vital signs of neural function or a heartbeat are temporarily so minimal as to be almost imperceptible. Such temporary, reversible mimicry of death is well-known to occur in patients suffering from these conditions, although it is not well-understood. For this reason, physicians have traditionally delayed brain-death testing for hours (in hypothermia) or up to three days (for barbiturate clearance) until these "confounding variables" have resolved, ${ }^{36}$ based on an awareness that such patients may recover.

${ }^{35}$ See Medical Consultants on the Diagnosis of Death to the President's Commission for the Study of Ethical Problems in Medicine and Biomedical and Behavioral Research, "Guidelines for the Determination of Death" (1981) 246:19 JAMA 2184 ("[c]riteria for reliable recognition of death are not available in the presence of hypothermia ... Hypothermia can mimic brain death by ordinary clinical criteria" and "[d]rug intoxication is the most serious problem in the determination of death ... Cessation of brain functions caused by the sedative and anesthetic drugs, such as barbiturates, benzodiazepines, [etc.] ... may be completely reversible even though they produce clinical cessation of brain functions and electrocerebral silence" both at 2186). The reversible death-like effect of cold and other variables was known as early as 1910-1950: Martin S Pernick, "Brain Death in a Cultural Context: The Reconstruction of Death, 1967-1981" in Stuart J Youngner, Robert M Arnold \& Renie Schapiro, eds, The Definition of Death: Contemporary Controversies (Baltimore: Johns Hopkins University Press, 1999) 3 at 5.

${ }^{36}$ See Paul A Byrne \& Richard G Nilges, "The Brain Stem in Brain Death: A Critical Review" (1993-94) 9:1 Issues L \& Med 3 at 6-7. The authors explain that "[i]n cases of suspected intoxication no declaration of death should be made at least until the drug is known to have been metabolized. The waiting period should be at least three days to cover phenobarbital, a drug with a long half-life (fifty or more hours). New drugs, especially illicit drugs, do not have a known half-life": ibid at 6. Complicating matters, the authors also argue that "drug blood levels lag behind brain levels" (ibid) so that tests showing drug clearance from blood might be an unreliable guide to whether drug residues still affect the brain. 
This empirical observation indicates that, in contrast to the President's Commission's claims, a temporary, total loss of neurological functioning, potentially lasting several days and sufficient to cause a disappearance of emergent functions (e.g., neural responsiveness), is still insufficient to produce a permanent loss of integrated functioning of the organism as a whole, i.e., bodily death. As discussed later in this paper, something more appears to be required in order for the temporary loss of integration and emergent properties to become permanent, causing physical death.

A third difficulty with the master regulator theory is that it has long been known that at least some body functions vital to sustaining life are not in fact controlled by the brain. For over 100 years, it has been recognized that the source of the impulse triggering the beating of the human heart (and the heart of other vertebrates) is not the brain, as the master regulator view implies, but individual heart cells themselves, which are then synchronized to beat together as a unit by electrical signals that come not from the brain but from the "sinus node," a structure within the heart. ${ }^{37}$ Thus, the source of the heartbeat, which circulates vital, oxygenated blood to the body, is the heart itself, not the brain. Because the impulse for the heartbeat originates within the heart, requiring no central nervous system input, vertebrate hearts are termed "myogenic," contrasting with the "neurogenic" hearts of some invertebrates. ${ }^{38}$

The vertebrate heart is therefore said to possess "inherent rhythmicity," 39 meaning that as long as its component cells remain oxygenated and healthy, the heart will beat independently, coordinated by its internal pacemaker cells, without brain input. There is some minor, brain-based influence by the vagus nerve of the brain stem. However, the vagus is not the source of the heartbeat's stimulus during life, nor does it stop the heart from beating in death. The vagus's influence simply fine-tunes the rate of an existing heartbeat. The heartbeat's lack of origin within the brain was acknowledged by the second US bioethics commission justifying the continued acceptance of brain death

${ }^{37}$ Mark E Silverman \& Arthur Hollman, "Discovery of the Sinus Node by Keith and Flack: On the Centennial of Their 1907 Publication" (2007) 93:10 Heart 1184 at 1184-87.

${ }^{38}$ Richard W Hill, Gordon A Wyse \& Margaret Anderson, Animal Physiology, 2d ed (Sunderland, Mass: Sinauer Associates, 2008) at 615, 617.

${ }^{39}$ President's Council, supra note 11 at 28. 
for determining legal death, the 2008 President's Council on Bioethics: "[T]here is no part of the CNS [central nervous system] that is absolutely indispensable for heart contractions in the way that the respiratory center in the brainstem is absolutely indispensable for the muscular contractions involved in breathing." 40

Oxygenation and heartbeat are interdependent. ${ }^{41}$ In contrast to the heartbeat, the stimulus for respiratory rhythm (breathing) does originate in a portion of the brain, specifically thought to be the "pre-Bötzinger complex" within the ventral respiratory group of brain stem neurons. ${ }^{42}$ If an injury to this brain stem complex destroys the stimulus for independent breathing, ventilator assistance can oxygenate the lungs and, through them, the blood circulated by the heart. Expert testimony suggests that, while eight to ten minutes of anoxia can produce necrosis of the brain (except the brain stem), an additional 15-18 minutes of anoxia results in brain stem necrosis, ${ }^{43}$ potentially affecting the pre-Bötzinger complex. Given that the heartbeat is autonomously generated rather than triggered by the brain (as described above), the master regulator theory lacks an account as to how brain death could produce cessation of the heartbeat.

It should be stressed here that a ventilator merely supplies oxygen to the lungs, thereby oxygenating the blood that will be redistributed to the body by an already-beating heart, and in turn nourishing all the body tissues, includ-

${ }^{40}$ Ibid [emphasis in original].

${ }^{41}$ For the dependence of heartbeat on breathing, see Bernat, "Whole-Brain Defense", supra note 5 at 21 ("in the absence of breathing, heartbeat stops within minutes" at 21). The reverse - i.e., that when a pulse is absent, breathing too will have ceased appears medically well-accepted as well. For example, advanced cardiac life support manuals suggest that the situation of a pulseless, yet still breathing, patient seems not to exist; see e.g. Joseph J Mistovich, Randall W Benner \& Gregg S Margolis, Prehospital Advanced Cardiac Life Support, 2d ed (Upper Saddle River, NJ: Pearson Prentice-Hall, 2004) at 305.

${ }^{42}$ See Allan Siegel \& Hreday N Sapru, Essential Neuroscience, 2d ed (Philadelphia: Lippincott Williams \& Wilkins, 2011) at 401. Alternatively, a heart-lung bypass machine can circulate oxygenated blood to the body.

${ }^{43}$ Canada, Law Reform Commission, Working Paper No 23: Criteria for the Determination of Death (Ottawa: Minister of Supply and Services, 1979) at 13-14 [Law Reform Commission]. 
ing the heart tissues that generate the heartbeat. By merely supplying oxygen, a ventilator does not force the heart to beat, nor can it restart the beating of a heart whose pulse has stopped. Thus, it would be inaccurate to state that the ventilator "forces" a patient to remain "artificially alive."

A final difficulty with the master regulator theory involves evidence that cardiopulmonary collapse does not in fact always ensue quickly after brain death, as has been claimed. In a meta-analysis of approximately 175 braindead patients, Shewmon found that when organs were not harvested and ventilator support not removed (contrasting with common treatment following brain death), whole-brain death was sometimes compatible with bodily "survival" - as indicated by emergent processes such as growth, wound healing, immune response, pubertal development, fetal gestation, etc. - occurring well beyond the "few days" predicted. ${ }^{44}$ In one ventilated body, these emergent processes continued for a full 20 years after whole-brain death determination, that diagnosis being confirmed by Shewmon and another research team. ${ }^{45}$ The 2008 President's Council on Bioethics conceded the soundness of Shewmon's evidence that brain death was in fact compatible with continued, integrated body functions, stating, "The bodies of these patients do not 'come apart' immediately upon succumbing to total brain failure [i.e., brain death]." ${ }^{.6}$ The Council agreed that the earlier view of the brain as the "inte-

${ }^{44}$ Shewmon, "Critical Re-evaluation”, supra note 6 at 135-36, 139.

45 Ibid at 136 (describing the patient's body, which, during 15 years on a ventilator, had grown and continued to circulate blood independently, assimilate nutrients by feeding tube, eliminate wastes, and perform many other functions). Regarding the same patient, see also Susan Repertinger et al, "Long Survival Following Bacterial Meningitis-Associated Brain Destruction” (2006) 21:7 J Child Neurol 591 at 592, 594. After 20 years of ventilator support, the patient's heart stopped and he was pronounced dead on a cardiopulmonary criterion. Brain autopsy found a totally calcified ball containing no identifiable brain or cellular structures, which "confirmed that his brain had been destroyed ... whereas his body remained alive (brain death with living body) for an additional two decades": ibid at 594.

${ }^{46}$ President's Council, supra note 11 at 39 . The President's Council did not dispute the findings of Shewmon's meta-analysis, which it augmented with updated information regarding his longest-persisting patient: ibid at 54. It recognized the work of researchers such as Shewmon as having "soundly criticized" the "exaggerated claims" of the earlier master integrator brain death rationale, and as having "persuasively called into question" the "supposed facts" regarding brain-dead bodies" lack of somatic integration and inability to maintain circulation: ibid at 39-40, 90. 
grator of the body's many and varied functions" is incorrect. ${ }^{47}$ Accordingly, a view of brain death equated with the loss of somatic integration of the "organism as a whole" could not continue to be the biological basis of neurological death. Yet despite abandoning this traditional biological explanation, the President's Council ultimately upheld the whole-brain death criterion, though using a different biological rationale, as discussed in the following section. ${ }^{48}$

\section{B. The Neurological "Self-Preserving Work" of the Organism as a Whole}

The 2008 President's Council somewhat confusingly justified its continued support for equating whole-brain death (or "total brain failure") with death of the entire patient. While the Council accepted Shewmon's metaanalysis as sufficient evidence for it to abandon the view of the brain as master integrator, ${ }^{49}$ it nevertheless did not accept Shewmon's data as sufficient evidence to declare that life continued in ventilated, brain-dead bodies displaying such properties as wound healing, fighting infection, or temperature homeostasis. ${ }^{50}$ Instead, as explained below, the Council clarified that only

${ }^{47}$ Ibid at 40 [emphasis in original]. The Council went on to state,

There may be, however, a more compelling account of wholeness that would support the intuition that after total brain failure [i.e., whole-brain death] the body is no longer an organismic whole and hence no longer alive. That account ... offers a superior defense for "total brain failure" as the standard for declaring death. With that account, death remains a condition of the organism as a whole and does not, therefore, merely signal the irreversible loss of so-called higher mental functions. But reliance on the concept of "integration" is abandoned and with it the false assumption that the brain is the "integrator" of vital functions [ibid at 60 [emphasis in original]].

${ }^{48}$ Ibid at 90. See also ibid at x ("the Council has concluded that the neurological standard [for determination of brain death] remains valid"); ibid at 12 ("[i]n the majority view of the Council ... today's 'whole-brain standard' [for determination of death] is, in fact, conceptually sound").

${ }^{49}$ See discussion in note 46, supra.

${ }^{50}$ President's Council, supra note 11 at 60 . The Council accepted that if these observations were taken as evidence of life in brain-dead bodies, then total brain failure (whole-brain death) could not be the criterion for organismic death. Ultimately, the Council opted to uphold whole-brain death as the criterion of organismic death, in- 
certain persistent properties in a body should be deemed diagnostic of "life." Thus, the Council retained the concept of the organism as a whole, and with it, the view that death represents the irreversible loss of that organism as a whole. However, it defined the concept differently than the earlier President's Commission had done.

The Council now based its conception of the organism as a whole on the idea that a living organism performs certain characteristic, vital, selfpreserving "work"; on this view, a dead organism is therefore one that has irreversibly lost the ability to perform that characteristic work. ${ }^{51}$ The "work" diagnostic of a living organism, the Council said, involves activities that demonstrate openness to stimuli and signals from the surrounding world, an ability to act selectively upon the world, and a "basic felt need" driving the organism to act. ${ }^{52}$ Regarding this vital work, the Council also stated:

[T] he fundamental vital work of a living organism ... [is] the work of self-preservation, achieved through the organism's needdriven commerce with the surrounding world.

And:

To preserve themselves, organisms must - and can and do - engage in commerce with the surrounding world ... reaching out into the surrounding environment to secure the required sustenance. This is the definitive work of the organism ... and what distinguishes every organism from non-living things. ${ }^{53}$

However, the Council concluded that only certain activities reveal the necessary degree of openness to, and engagement with, the world; it is not sufficient for an entity to merely exchange any kind of material with the surrounding world. In this regard, the Council stressed that the capacity to

dicating it did not accept these properties as evidence of life, with the majority agreeing that "the patient with total brain failure is no longer able to carry out the work of a living organism": ibid at 90.

${ }^{51}$ Ibid at 60-61 (describing this viewpoint as one of two alternatives under study); ibid at 90-91 (adopting that viewpoint as the majority's position).

${ }^{52}$ Ibid at 61.

${ }^{53}$ Ibid at 60-61 [emphasis in original]. 
breathe spontaneously should be considered diagnostic of living organisms. ${ }^{54}$ A second feature that it considered diagnostic of living things was consciousness. ${ }^{55}$ In the Council's view, these two features reveal that an organism engages in sufficient commerce with the world to be characterized as living.

The Council further elaborated its reasoning that certain exchanges with the environment - such as the intake of oxygen in breathing - were more indicative of life than other exchanges, explaining, "Self-preserving commerce with the world ... involves more than just openness or receptivity. It also requires an ability to act on one's own behalf - to take in food and water, and even more basically, to breathe." 56 The Council elsewhere suggested that the drive to breathe was more indicative of life because it was more "appetitive" than other exchanges. ${ }^{57}$ It articulated the position that spontaneous breathing reveals not only openness and ability to act upon the world, but also an "inner experience of need" or "drive to breathe." 58

Yet the Council's reasons for narrowing the range of qualifying "work" diagnostic of living organisms are unpersuasive in several ways. First, the Council did not adequately clarify, in scientific terms, why oxygen intake qualifies, but why other equally vital-seeming processes (such as food and water intake) do not, in the Council's opinion, constitute a necessary element

${ }^{54} \mathrm{Ibid}$ at $62-63$.

${ }^{55}$ Ibid at 61 (" $[\mathrm{t}] \mathrm{o}$ preserve itself, an organism must be open to the world ... In higher animals, including man, [such openness] is evident most obviously in consciousness or felt awareness, even in its very rudimentary forms").

${ }^{56}$ Ibid at 62.

${ }^{57}$ See ibid at 63 (footnote):

Shewmon misses the critical element: the drive exhibited by the whole organism to bring in air ... By ignoring the essentially appetitive nature of animal breathing, Shewmon's [meta-analysis conclusion] misses the relevance of breathing as incontrovertible evidence that "the organism as a whole" continues to be open to and at work upon the world, achieving its own preservation ... Bringing air into the body is an integral part of an organism's mode of being as a needy thing. More air will be brought in if metabolic need demands it and the body feels that need, for example during exercise [emphasis in original].

${ }^{58}$ Ibid at 62. 
of openness, the ability to act, or an appetitive, inner experience of need. Second, the Council's reasons for requiring spontaneity (i.e., independence of technological assistance) specifically in relation to breathing are also not convincing.

A number of scientific errors, inconsistencies, and other puzzling features also appear in the Council's discussion of why brain death is death of the body. For example, the Council's focus on breathing as one of two vital features of the living organism as a whole seems to be lacking in scientific foundation. While suggesting that breathing is more "appetitive" and "even more basic" to life than the intake of other substances such as nutrients, the report does not define the term "appetitive." Elsewhere, breathing is discussed in terms of a felt need or inner drive. ${ }^{59}$ "Appetitive" may therefore be intended by the Council to refer to the possession of a basic internal "appetite" or drive to ingest something, in order to meet a hunger or felt need. In view of the Council's discussion of the functional brain stem in relation to breathing and the existence of the living organism as a whole,${ }^{60}$ the idea of breathing as appetitive may have originated in thinking of it as a brainmediated function. Yet if so, the Council's choice of breathing over all other drives seems misguided. Breathing is mediated by part of the brain, but so too are the appetites for food, water, and various other needs. The drive to breathe is triggered in a healthy brain stem by a buildup of carbon dioxide and hydrogen ions in the cerebrospinal fluid ("CSF") and blood. ${ }^{61}$ Ordinarily, when brain stem chemoreceptors detect this body signal, they respond by neurologically triggering the diaphragm and intercostal muscles to make

${ }^{59}$ See ibid at 62 ("even when the drive to breathe occurs in the absence of any selfawareness, its presence gives evidence of the organism's continued impulse to live"). Later the Council observes, "The striving of an animal to live, a striving we can discern even in its least voluntary form (i.e., breathing), indicates that we still have among us a living being": ibid at 64 (footnote).

${ }^{60}$ See ibid at 32-33 ("'[o]ne marker of brainstem function ... [is] the signal that is sent from the respiratory centers to the muscles of respiration. Thus, the patient's drive to breathe [created by that signal] must be tested with an apnea test " [emphasis in original]); ibid at 31 ("the functions that depend on the brainstem are central to the basic work of the organism as a whole. This has already been noted with respect to the brainstem's ... involvement in breathing").

${ }^{61}$ Gerard J Tortora \& Bryan Derrickson, Introduction to the Human Body: The Essentials of Anatomy and Physiology, 9th ed (Hoboken, NJ: John Wiley \& Sons, 2012) at 500-01. 
breathing movements, allowing the lungs to release carbon dioxide and take in oxygen. Response to nutrient needs is similarly brain-mediated. The hormone leptin signals to the brain - specifically the hypothalamus ${ }^{62}$ - when the body's fat tissues indicate low triglyceride levels. ${ }^{63}$ On receiving this signal, the brain produces hunger pangs and a drive to ingest nutrients ${ }^{64}-$ an "appetite" in the traditional sense of the word.

Therefore, if the Council's basis for distinguishing breathing from feeding is that breathing is brain-mediated, then it is inconsistent for it to disregard the similarly brain-mediated drive to ingest nutrients. Both urges are brain-mediated, both are communicated by specific chemical signals received in the brain, and in both, the relevant brain-mediated responses - a neurological impulse triggering the thoracic muscles to breathe and a neurological impulse to ingest food - possess consciously and unconsciously controlled aspects. Both seem to reflect a strong inner drive, the source of which is discussed later in this paper. A noteworthy difference between breathing and eating may lie in the timing of the consequences that flow from an unmet appetite. In the case of nutrient ingestion, the body can - for a time - internally recycle its own tissues, such as muscle, to obtain needed nutrients and energy with which to counteract the effects of entropy. However, such recycling has negative health consequences, so the body cannot do this indefinitely or it will eventually starve to death, within weeks or months. Fresh nutrients must be ingested from the environment for the body to remain alive. In the case of breathing, internal recycling of oxygen is not possible in animals, so the consequences of an interrupted oxygen supply from the environment accrue more rapidly, with death resulting in only a matter of minutes. But while timing differs, the drives for both air and nutrients appear very strong. For reasons to be made clear below, self-preservation of the organism as a whole requires that both urges be met within appropriate time

\footnotetext{
62 Mark F Bear, Barry W Connors \& Michael A Paradiso, Neuroscience: Exploring the Brain, 3d ed (Philadelphia: Lippincott Williams \& Wilkins, 2007) at 513.

${ }^{63}$ Tortora \& Derrickson, supra note 61 at 99.

${ }^{64}$ Bear, Connors \& Paradiso, supra note 62 at 514.
} 
periods. Therefore, there seems to be no obvious basis on which to distinguish breathing and nutrient ingestion as the Council does. ${ }^{65}$

There also appears to be no obvious reason why breathing must be spontaneous to indicate life. In the Council's words:

The natural work of breathing, even apart from consciousness or self-awareness, is itself a sure sign that the organism as a whole is doing the work that constitutes - and preserves - it as a whole. In contrast, artificial, non-spontaneous breathing produced by a machine is not such a sign ... of the organism as a whole. It is not driven by felt need, and the exchange of gases that it effects is ... [not] a sign of [the organism's] genuine vitality. ${ }^{66}$

Yet if being driven by felt need is what characterizes a process as being diagnostic of life, then it is unclear why the means of oxygen supply is relevant. Immediately prior to the mechanical supply of oxygen, an appetitive "felt need" for oxygen will be experienced by the body's cells, tissues, and systems, and this drive will be communicated to the brain stem, regardless of whether the brain stem can translate that signal into action. Technological assistance with oxygen delivery to the body simply replaces the response to the felt need, not the body's felt need or drive to obtain oxygen itself. In addition, if the artificially supplied oxygen were not meeting a genuine need felt by the body at the cellular, tissue, and system levels, the heart of a patient on a ventilator would not continue to beat. A heartbeat is something the ventilator does not and cannot produce without the body's continued internal vitality or "life."

By similar reasoning, the Council's conclusion that a patient with total brain failure "has lost - and lost irreversibly - a fundamental openness to the surrounding environment, as well as the capacity and drive to act on this environment on his or her own behalf ${ }^{\prime 67}$ seemingly fails as well. In a braindead individual, the brain stem is irreversibly damaged, meaning that the in-

${ }^{65}$ A similar argument can be made regarding an organism's drive to ingest water and avoid dehydration, which is also brain-mediated: ibid at 527. This drive becomes urgent when unmet for a period of hours to days.

${ }^{66}$ President's Council, supra note 11 at 63 [emphasis in original].

${ }^{67}$ Ibid at 90 [emphasis added]. 
dividual has lost part of its capacity to act on the world, but not all of it, nor has it lost its drive to act. The same appetitive need for oxygen and the same rise in the waste product carbon dioxide that signals that need to the (unreceptive) brain stem are still present. The damaged brain stem is simply unable to translate that signal into the neurological impulse for chest breathing movements. But it does not follow that the body's drive - i.e., its tissues' felt need for oxygen - is irreversibly eradicated. By taking in supplied oxygen and maintaining a heartbeat, such bodies indicate a retained openness and inner drive to obtain and use oxygen. Were that not the case, there would be no pulse in a ventilator-supported brain-dead body. Where a pulse exists in such a body, the Council's definition of death of the organism as a whole does not seem to be made out, since neither the drive nor the capacity to act is entirely or irreversibly gone.

Some noteworthy scientific errors also seem to have been made by the Council in reaching its final conclusion. For instance, it writes:
When a PVS [persistent vegetative state] patient tracks light with his or her eyes, recoils in response to pain, swallows liquids placed in the mouth, or goes to sleep and wakes up, such behav- iors - although they may not indicate self-consciousness - testify to the organism's essential, vital openness to the surrounding world. An organism that behaves in such a way cannot be dead. $^{68}$

Given that the Council's report had the potential to prompt a shift to a higher-brain criterion of death (which would have resulted in PVS patients being considered brain-dead), the diagnostic picture of PVS in the Council's treatment of brain death should have been a well-researched topic. Yet some elements of the above claim suggest a lack of familiarity with PVS on the part of the Council. According to the 1994 report of American Academy of Neurology's Multi-Society Task Force on PVS, ${ }^{69}$ which remains the current authority for PVS diagnostic criteria, most PVS patients fail to track light with their eyes ${ }^{70}$ and all fail to recoil from pain, ${ }^{71}$ while some fail to retain the

\footnotetext{
${ }^{68}$ Ibid at 61 [emphasis in original].

${ }^{69}$ Multi-Society Task Force on PVS, Consensus Statement, "Medical Aspects of the Persistent Vegetative State (First of Two Parts)" (1994) 330:21 New Eng J Med 1499.
}

${ }^{70}$ Ibid at 1500. 
ability to swallow liquids placed in the mouth. ${ }^{72}$ Of the Council's list, only the circadian rhythmicity of sleep-wake behaviours is reliably retained in PVS, ${ }^{73}$ reducing the Council's list of life's distinguishing features in these patients to potentially just one in some cases. In such a case - i.e., in the absence of all the other criteria - would the Council still defend the ability of a patient to open or close his or her (possibly sightless) eyes and engage in sleep every 12 hours as sufficient evidence to qualify that patient as living? Instead, one might reasonably ask why the PVS patient's spontaneous heartbeat - a feature shared with ventilated, brain-dead bodies - was not mentioned by the Council as being diagnostic of life in such patients, as has often been the case in other discussions of PVS. ${ }^{74}$

To be clear, the argument regarding PVS patients has been made here to illustrate the apparent inadequacy of the Council's chosen distinguishing features of "life," rather than to support reclassifying PVS patients as dead. Recent studies suggest PVS patients may possess more awareness than has been externally evident, or explored, in the past. ${ }^{75}$ Nonetheless, it remains noteworthy that many of the reasons the Council supplied to justify PVS patients' retention among the living (in contrast to brain-dead patients) are in fact frequently inapplicable to these patients.

Finally, the report's choice of consciousness as the second, equally vital characteristic of a living organism also contains puzzling elements. For example, the Council stresses that the cortically mediated awareness aspect of consciousness can rescue apneic spinal-injury patients from being considered

${ }^{71}$ Ibid at 1500 (" $[\mathrm{t}]$ he vegetative state can be diagnosed according to the following criteria: ... (2) no evidence of sustained, reproducible, purposeful, or voluntary behavioral responses to visual, auditory, tactile, or noxious stimuli").

${ }^{72}$ Ibid at 1501 ("[i]n most [i.e. not all] patients, the gag, cough, sucking, and swallowing reflexes are preserved").

${ }^{73}$ Ibid at 1500 (" $[\mathrm{t}]$ he vegetative state can be diagnosed according to the following criteria: ... (4) intermittent wakefulness manifested by the presence of sleep-wake cycles").

${ }^{74}$ See Bernat, Culver \& Gert, supra note 11 at 391.

${ }^{75}$ For instance, evidence now suggests that some PVS patients can understand and respond to instructions to perform mental tasks: see Adrian M Owen et al, "Detecting Awareness in the Vegetative State" (2006) 313:5792 Science 1402. 
dead, despite their being unable to act on the world at the macroscopic level. ${ }^{76}$ Yet elsewhere in its report, it appears to prioritize the brain-stemmediated wakefulness aspect of consciousness as more important in indicating the life of an organism as a whole:

Position Two [which the Council ultimately accepts] ... tak[es] the loss of the impulse to breathe and the total loss of engagement with the world as the cessation of the most essential functions of the organism as a whole.... From this philosophicalbiological perspective, it becomes clear that a human being with a destroyed brainstem has lost the functional capacities that define organismic life. ${ }^{77}$

This is an odd claim, given the Council's ultimate support for a whole-brain criterion of death. ${ }^{78}$ The Council adds an explanatory claim that:

if a brain injury has progressed to the point at which the [relatively resilient] brainstem retains no function, it has probably ravaged the more fragile parts of the brain as well. Thus, the bedside tests for brainstem function are tests for the extent of destruction both to the brainstem and to the ... [cortical] "higher centers." $^{\text {,79 }}$

Yet this is untrue of isolated brain stem injuries where the cortex remains unimpaired, a fact the report only acknowledges in a footnote. ${ }^{80}$ Overall, by focusing on the brain stem and brain-stem-mediated characteristic of wakeful-

76 The Council explained that "patients with spinal cord injuries may be permanently apneic or unable to breathe without ventilatory support and yet retain full or partial possession of their conscious faculties. Just as much as striving to breathe, signs of consciousness are incontrovertible evidence that a living organism, a patient, is alive": President's Council, supra note 11 at 64 . But, it continued, "[i]f there are no signs of consciousness and if spontaneous breathing is absent and if the best clinical judgment is that these neurophysiological facts cannot be reversed, Position Two [the conclusion the Council majority ultimately accepts] would lead us to conclude that a once-living patient has now died": ibid [emphasis in original].

${ }^{77}$ Ibid at 66 [emphasis added].

${ }^{78}$ Ibid at $60,89$.

${ }^{79}$ Ibid at 32.

${ }^{80} \mathrm{Ibid}$ at 32 (footnote). 
ness, rather than giving similar emphasis to the cortex and cortically mediated characteristic of awareness, the Council appears to argue more strenuously for a brain stem criterion of death than for the whole-brain criterion it ultimately supports. The President's Council's report may therefore anticipate and pave the way for acceptance of a brain stem criterion of death in the United States, as has been adopted in the United Kingdom and, more recently, in Canada.

Interestingly, the Council's emphasis on the self-preserving nature of the work of a living organism as a whole was foreshadowed in earlier statements describing brain death from a view based on "thermodynamic and information theory." In Bernat's words, "[a]s ... explained using thermodynamic theory, the brain is the critical and irreplaceable system of the organism without which the organism no longer can actively oppose entropy." 81 According to this view, which originated with Julius Korein, a functioning nervous system is necessary for an organism to resist entropy, and without it, the organism can be considered "dead." Later, Korein together with Calixto Machado clarified that the brain's behavioural "output patterns direct the [organism] as a whole towards behavior that will increase survival of the individual ... [so that] decision-making processes occurring within the brain result in behavioral output patterns that tend to increase the organism's own organization." 82 That is, they decrease its entropy.

Korein and Machado asserted that "[t]he irreplaceable functioning brain, specifically and especially in an individual adult member of the species Homo sapiens overwhelmingly defines the behavior of the system-as-a-whole [i.e., the organism as a whole] towards decreasing entropy production." ${ }^{83}$ It is possible, in making this claim, that Korein and Machado intended the term "behaviour" only to refer to the sorts of mental choices and decisions undertaken at a macroscopic level by an organism, such as those involved in planning how to apprehend prey for food or escape danger. These "behaviours"

${ }^{81}$ Bernat, "Whole-Brain Defense", supra note 5 at 20. Entropy is a thermodynamic concept describing the disorder in a body or system, relative to its surroundings.

82 Julius Korein \& Calixto Machado, "Brain Death: Updating a Valid Concept for 2004" in Calixto Machado \& D Alan Shewmon, eds, Advances in Experimental Medicine and Biology, vol 550: Brain Death and Disorders of Consciousness (New York: Springer Science+Business Media, 2004) 1 at 3.

${ }^{83}$ Ibid at 2. 
are brain-based and would indeed decrease the organism's level of entropy to some degree.

However, there is another possible interpretation of "behaviour" that does not focus on the mental choices of macroscopic individual organisms, but rather looks at the activities of the more microscopic elements within a system, including within an organism. On this latter interpretation, it would not be true to say that the functioning brain "overwhelmingly defines the behavior of the system-as-a-whole towards decreasing entropy production." As will become clear from the discussion below, entropy-resistance is the fundamental, signature property of all life - from simple to complex - but it is a process occurring at all levels, including most basically at the molecular lev$\mathrm{el}$, in the gathering and use of energy to resist the chaotic forces that break down cells. Although a functioning nervous system may permit an organism to engage in additional anti-entropic behaviours beyond the molecular level e.g. threat-evasion or food-hunting strategies by the whole organism - these are not essential to life in the same defining manner. In fact, the most prevalent anti-entropic functions of living organisms are those taking place below the whole-organism level, at the level of molecules, involving processes that have no neural component. As discussed later, in eukaryotes, the locus of molecular anti-entropic functioning is the mitochondrion. It is this organelle and not the brain that "overwhelmingly defines the behavior of the [organism]-as a-whole towards decreasing entropy production."

Whether reflecting Korein and Machado's intended or actual meaning, the claim that a functioning human (or other sophisticated) brain has an overwhelmingly significant effect on entropy reduction appears to have subsequently influenced the President's Council in its formation of the concept of the "self-preserving work" of the organism as a whole. The Council majority concluded that retaining brain death as a death criterion was justified on the basis that "the patient with total brain failure is no longer able to carry out the fundamental work of a living organism ... [i.e.,] self-sustaining, need-driven activities critical to and constitutive of its commerce with the surrounding world." 84 In using the term "self-sustaining," the Council implied that the work of the organism - specifically, maintaining consciousness and breathing spontaneously - enables that organism to overcome the chaotic forces that attempt to break it down, while the absence of such work makes it inevitable that the organism will irreversibly succumb to those forces:

${ }^{84}$ President's Council, supra note 11 at 90. 
"When these signs [of openness, capacity, and drive or felt need to act on the environment] are absent, and these [self-sustaining, need-driven] activities have ceased, then a judgment that the organism as a whole has died can be made with confidence. ${ }^{85}$ Yet from a mitochondrial perspective, as discussed later in this paper, this conclusion appears unfounded. Heart-beating, braindead bodies on ventilator support do exhibit signs of openness, felt need, and capacity to act, and can engage in self-sustaining, anti-entropic activities other than consciousness and spontaneous breathing.

There is, as supplied by Shewmon, abundant evidence that a brain-dead human body on ventilator support can resist entropy, despite lacking the neural function for consciousness or spontaneous breathing. In Shewmon's meta-analysis, the bodies of some brain-dead patients did not rapidly become uncoordinated, but in certain cases displayed wound healing and immune responses, indicating an ability to resist entropy at the tissue and system levels. ${ }^{86}$ Evidence-based medical protocols for the care of brain-dead patients intended for organ donation also clearly anticipate and rely on these braindead bodies having the capacity to take up, metabolize, and utilize oxygen, nutrients, pharmaceuticals, or transfused blood, in the same way as a living human body. ${ }^{87}$ Such care is provided specifically to optimize the functionality of harvested organs, by allowing these brain-dead bodies a chance to reverse some physical damage, indicating medical knowledge of a capacity for entropy-resistance in the brain-dead:

It is important to take the necessary time in the ICU to optimize multi-organ function to improve transplant outcomes. Reversible organ function can be improved ... Once organ function is optimized, surgical procurement should be arranged emergently. ${ }^{88}$

Clearly, this preserved capacity for entropy-resistance in the bodies of braindead patients cannot flow from brain functions that have been destroyed (unless misdiagnosis of brain death is widespread). Therefore, as clarified later

${ }^{85}$ Ibid at 90-91.

${ }^{86}$ Shewmon, "Critical Re-evaluation”, supra note 6 at 136, 139.

${ }^{87}$ Sam D Shemie et al, "Organ Donor Management in Canada: Recommendations of the Forum on Medical Management to Optimize Donor Organ Potential" (2006) 174:6 Can Med Assoc J S13 at S16, S18.

${ }^{88}$ Ibid at $\mathrm{S} 21$. 
in this paper, a functioning human brain is not necessary for the whole organism to resist entropy and be considered "living."

Ultimately, in accepting whole-brain death, the President's Council's conclusion may have provided the public and health care providers alike with a reassuring sense of consistency with the conclusions of the earlier President's Commission, as well as convenience in continuing to facilitate the worthy objectives of organ transplantation. Yet in terms of its substance, the President's Council's "self-preserving work" rationale appears as inadequate in explaining why brain death should be considered synonymous with human death (death of the organism as a whole) as was the earlier President's Commission's master regulator rationale. As discussed in Part IV below, this inadequacy may have important implications for the informed consent process for procedures such as organ donation, where patient consent is legally required to be free, informed, and competent. The free and informed nature of consent could be jeopardized by scientifically inaccurate information about brain death - that is, that the biological reality of brain death may differ from what patients have been led to understand - and this in turn could invalidate any consent given.

\section{Death: A Mitochondrial Account}

What follows is an alternative account of processes of life and death from a body-centred perspective, which seems to better account for empirical observations than earlier accounts. The ensuing discussion clarifies how, at the levels of cells, tissues, and whole organisms, this alternative view has more explanatory power regarding death's idiosyncratic features, as well as greater scientific support and internal consistency than earlier scholarship such as the President's Commission and President's Council reports. However, it should be noted that during this next section of the discussion, we are simply discussing biological death rather than the legal criteria to be used to indicate when death has occurred in order to permit certain actions, such as burial, to take place. The latter are points that will be taken up in Part IV of the paper.

An alternative account of the biological phenomenon of death - in humans, non-human vertebrates, and other eukaryotes ${ }^{89}$ - can be made based

${ }^{89}$ Eukaryotes, e.g., plants, animals, and fungi, are organisms whose cells possess nuclei. All extant eukaryotes have, or once had, mitochondria. 
on death's bioenergetic aspects. Energy use is an important characteristic of all living things..$^{90}$ Energy is required for life processes: growth, development, repair, movement, reproduction, and internal temperature homeostasis in the body. ${ }^{91}$ Energy use allows organisms to resist entropic forces that would otherwise irreversibly damage the body's cells and disperse vital cell components (e.g., DNA) throughout the inanimate environment. As physicist Erwin Schrödinger observed, entropy reduction is a fundamental, signature feature of all known life. ${ }^{92}$ In contrast to the position of some neurologists cited by the President's Council that destruction of the whole brain dooms the body to "los[e] its integrity as an entropy-resistant system," ${ }^{93}$ the reality

${ }^{90}$ Energy flow and entropy resistance are key components of "life." All known domains of life share the same mechanism for acquiring energy for life processes from "food": an electron transport chain, coupled with a process for pumping protons across a cell membrane, creating a chemical gradient whose potential energy becomes stored in chemical bonds of adenosine triphosphate ("ATP"), the "universal energy currency." Nick Lane writes, "[P] umping protons across a membrane [to produce chemical energy] is as much a signature of life on Earth as DNA. It is fundamental": Nick Lane, Power, Sex, Suicide: Mitochondria and the Meaning of Life (New York: Oxford University Press, 2005) at 91 [Lane, Power]. Mitochondrial researcher Douglas Wallace likewise writes, "[1]ife is the interplay between structure and energy": Douglas C Wallace, "A Mitochondrial Paradigm of Metabolic and Degenerative Diseases, Aging, and Cancer: A Dawn for Evolutionary Medicine" (2005) 39 Annu Rev Genet 359 at 359 [Wallace, "Mitochondrial Paradigm"].

${ }^{91}$ Maintaining a certain stable internal temperature allows biochemical reactions to take place at an efficient rate.

92 “[A] living organism continually increases its [positive] entropy ... and thus tends to approach the dangerous state of maximum entropy, which is death. It can only keep aloof from it, i.e. alive, by continually drawing from its environment negative entropy ... What an organism feeds upon is negative entropy.... [T] thing in metabolism is that the organism succeeds in freeing itself from all the entropy it cannot help producing while alive": Erwin Schrödinger, What is life? and Other Scientific Essays (Garden City, NY: Doubleday \& Company, 1956) at 71. James Lovelock adopts a similar view: "[L]ife is a member of the class of phenomena which are ... able to decrease their internal entropy at the expense of substances or free energy taken in from the environment and subsequently rejected in a degraded [i.e., higher entropy] form": James Lovelock, Gaia: A New Look at Life on Earth (New York: Oxford University Press, 1995) at 4.

${ }^{93}$ President's Council, supra note 11 at 41. 
appears to be otherwise. Entropy reduction exists at the most basic molecular level, in organisms ranging from the simplest bacteria to more complex, multicellular eukaryotes including humans. In eukaryotes, the cellular organelle known as the mitochondrion is the predominant site of energy production and is responsible for much of the entropy-resistance.

1. The importance of mitochondria in cellular life

In eukaryotes, all of the traditionally noted empirical observations of death may be explained as effects on the mitochondrion. ${ }^{94}$ Most human tissues contain 500-2,000 mitochondria per cell, although heart cells, having high energy requirements, may contain 2,000-200,000 mitochondria each. ${ }^{95}$ Dubbed the cell's "powerhouse," 96 this subcellular structure features protein "electron transport chains" embedded in its inner membrane. Mitochondrial energy production, termed "cellular respiration," electrons through these chemical chains. This process pumps protons across

94 This article will not focus on non-eukaryotic processes. In non-eukaryotes (all of which are single-celled organisms that do not have a nucleus, for example, bacteria), life and death do not involve mitochondrial processes, because mitochondria do not exist in these organisms. Because bacteria reproduce by simple division, it may, strictly speaking, be slightly more complicated to discuss whether a single bacterial cell is entirely dead, once its contents have been subdivided among generations of surviving "daughter" bacterial cells. Bacterial life is made possible by membranes that both contain vital contents and, among photosynthetic bacteria like the ancestor of the mitochondria, also manufacture energy: see Lane, Power, supra note 90 at 91 . This being the case in life, one may reasonably speculate that bacterial cell death may occur by disruption of the bacterial cell membranes' ability to produce energy and to protect cell contents.

95 Anna Gvozdjakova, "Mitochondrial Physiology" in Anna Gvozdjakova, ed, Mitochondrial Medicine: Mitochondrial Metabolism, Diseases, Diagnosis and Therapy (London: Springer, 2008) 1 at 1 [Gvozdjakova, "Mitochondrial Physiology"].

${ }^{96}$ Ibid.

${ }^{97}$ Mitochondrial respiration, i.e., "aerobic" respiration, is a chemical process in which fuel (food) molecules are converted to energy for use by the organism. It is not to be confused with the gas-exchange process of the lungs that is also referred to as "respiration." 
the inner mitochondrial membrane, capturing energy in the chemical bonds of adenosine triphosphate ("ATP") molecules. ${ }^{98}$

Ironically, given their vital importance to animal and other eukaryotic cells, mitochondria are only distantly related to their "hosts." Once thought to be of host-cell origin, mitochondria are now widely viewed as descendants of ancient, oxygen-requiring bacteria, ${ }^{99}$ which perhaps entered the first eukaryotic cell two billion years ago in a parasitic relationship that became symbiotic. ${ }^{100}$ Mitochondria retain recognizably bacterial DNA and other microbial similarities, ${ }^{101}$ such as antibiotic sensitivity. ${ }^{102}$ Significantly, mito-

${ }^{98}$ Mitochondria also release some energy as heat, permitting the body's internal temperature homeostasis: see Evangelos D Michelakis, "Mitochondrial Medicine: A New Era in Medicine Opens New Windows and Brings New Challenges" (2008) 117:19 Circulation 2431 at 2431; Douglas C Wallace, "Why Do We Still Have Maternally Inherited Mitochondrial DNA? Insights from Evolutionary Medicine" (2007) 76 Annu Rev Biochem 781 at 782 [Wallace, "Maternally Inherited Mitochondrial DNA"].

99 This position originated with Lynn Sagan's “endosymbiont theory”: see Lynn Sagan, "On the Origin of Mitosing Cells" (1967) 14:3 J Theor Biol 225. The eukaryotic-mitochondrial merger involved a rare combination of events that apparently occurred only once in the four billion years of Earth's history: Lane, Power, supra note 90 at 17,25 .

${ }^{100}$ Ibid at 44, 213-14. Lane also observes that the original relationship may have alternatively arisen not as parasitism but as predation (consumption) of the protomichondrion by the host cell, but in any case the relationship ultimately became symbiotic (ibid).

${ }^{101}$ Mitochondria possess bacterium-style ribosomes for protein manufacture, are haploid as bacteria are, and retain recognizably bacterial, circular (rather than linear) DNA, which differs from eukaryotic DNA in having no protective histones, no "junk DNA" stretches, and relatively poor DNA repair. There are thus two distinct sets of DNA within any eukaryotic cell (including human cells): the DNA of the mitochondrion and that of the host cell's nucleus: see ibid at 15, 279; Inna N Shokolenko, Susan P Ledoux \& Glenn L Wilson, "Mitochondrial DNA Damage and Repair" in Stephen W Schaffer \& M-Saadeh Suleiman, eds, Mitochondria: The Dynamic Organelle (New York: Springer, 2007) 323 at 323, 325.

102 See Joel N Meyer et al, "Mitochondria as a Target of Environmental Toxicants" (2013) 134:1 Toxicol Sci 1 ("[d]rugs have now been identified that inhibit ... mitochondrial protein synthesis (a common mode of toxicity of antibiotics that target bacterial ribosomes, to which mitochondrial ribosomes are similar due to mito- 
chondrial DNA is more susceptible to mutation and less easily repaired than host-cell (nuclear) DNA. ${ }^{103}$ Mitochondria reproduce under the combined direction of host cell and mitochondrion, ${ }^{104}$ and can only form from preexisting, viable mitochondria.

This relationship is a continuing symbiosis in which the nucleus of the host cell and the mitochondria function interdependently. ${ }^{105}$ Due to mitochondrial changes acquired during the two-billion-year relationship, mitochondria cannot live independently - nor be artificially cultured ${ }^{106}$ - outside host cells, so strong is their symbiotic dependence. Of originally 1,500 mitochondrial genes, a mere $37(2.5 \%)$ remain physically within the mitochondrion, the rest having been incorporated into host-cell nuclear DNA through

chondria's evolutionary origins)" at 3). See also Shokolenko, Ledoux \& Wilson, supra note 101 at 325-26; Lane, Power, supra note 90 at 15.

${ }^{103}$ See Shokolenko, Ledoux \& Wilson, supra note 101 at 330. Yet some mitochondrial DNA repair does occur: see Ricardo Gredilla, Vilhelm A Bohr \& Tinna Stevnsner, "Mitochondrial DNA Repair and Association with Aging - An Update" (2010) 45:7-8 Exp Gerontol 478.

104 See Emelie Braschi \& Heidi M McBride, "Mitochondria and the Culture of the Borg" (2010) 32:11 BioEssays 958 at 959.

105 See Wallace, "Maternally Inherited Mitochondrial DNA", supra note 98 at 781 (" $t$ the human cell is a symbiosis of two life forms: the nucleus-cytosol and the mitochondrion"). There is argued to exist "a complex symbiosis between [two] entities that are [each] partly dictated by a different set of DNA: the cell with all its metabolites and fuels on the one hand and the mitochondrion to generate the necessary energy-rich [ATP] on the other hand": Wim H Saris \& Steven B Heymsfield, "All Metabolic Roads Lead to Mitochondrial (Dys)-Function" (2007) 10:6 Curr Opin Clin Nutr Metab Care 661 at 661. Due to gene transfer to the cell nucleus, mitochondria can only produce certain vital proteins by inducing the host cell's nucleus to act. The few genes retained in the mitochondrion may allow especially rapid production of certain proteins, to enable quick adaptation to environmental changes: Wallace, "Maternally Inherited Mitochondrial DNA", supra note 98 at 800 . Mitochondrial changes relative to their bacterial ancestors seem minor compared with the radical transformation of host cells over the same time period: from bacterium-like (Archaean) single cells into the vast array of multicellular life, including humans, on earth today.

${ }^{106}$ Lane, Power, supra note 90 at 16. 
horizontal transfer over time. ${ }^{107}$ In the symbiotic bargain, host cells provide mitochondria with protection from external conditions and raw materials for growth, including vital enzymes that mitochondria can no longer produce for themselves due to previous mitochondrial gene transfer. In exchange, host organisms receive huge quantities of mitochondrial energy for life processes. In addition to directly affecting and regulating bioenergetic functions in the body such as metabolism and thermoregulation, mitochondria are also increasingly implicated as key organelles in a wide array of bodily functions, including the immune system, ${ }^{108}$ stem cell functioning, ${ }^{109}$ epigenetic alteration of nuclear DNA expression, ${ }^{110}$ and possibly circadian rhythms. ${ }^{111}$ Cer-

${ }^{107}$ Wallace, "Mitochondrial Paradigm", supra note 90 at 361.

108 Damien Arnoult et al, "Mitochondria in Innate Immunity" (2011) 12:9 EMBO Rep 901 at 901-02, 906, 909; Laura Vargas-Parada, "Mitochondria and the Immune Response" (2010) 3:9 Nature Education 15; A Phillip West, Gerald S Shadel \& Sankar Ghosh, "Mitochondria in Innate Immune Responses" (2011) 11:6 Nat Rev Immunol 389 at 389.

109 Sudip Mandal et al, "Mitochondrial Function Controls Proliferation and Early Differentiation Potential of Embryonic Stem Cells" (2011) 29:3 Stem Cells 486 at 486, 490; Claudia Nesti et al, "The Role of Mitochondria in Stem Cell Biology" (2007) 27:1-3 Biosci Rep 165 at 165, 167; Thomas Lonergan, Barry Bavister \& Carol Brenner, "Mitochondria in Stem Cells" (2007) 7:5 Mitochondrion 289 at 289, 291; Graham C Parker, Gyula Acsadi \& Carol A Brenner, "Mitochondria: Determinants of Stem Cell Fate?" (2009) 18:9 Stem Cells Dev 803 at 805; Kati J Ahlqvist et al, "Somatic Progenitor Cell Vulnerability to Mitochondrial DNA Mutagenesis Underlies Progeroid Phenotypes in Polg Mutator Mice" (2012) 15:1 Cell Metab 100 at 105.

${ }^{110}$ Patrick F Chinnery et al, "Epigenetics, Epidemiology and Mitochondrial DNA Diseases" (2012) 41:1 Int J Epidemiol 177 at 177, 180; Sheroy Minocherhomji, Trygve O Tollefsbol \& Keshav K Singh, "Mitochondrial Regulation of Epigenetics and Its Role in Human Diseases" (2012) 7:4 Epigenetics 326 at 326; Douglas C Wallace \& Weiwei Fan, "Energetics, Epigenetics, Mitochondrial Genetics" (2010) 10:1 Mitochondrion 12 at 12, 21-23; DC Wallace, "Mitochondria, Bioenergetics, and the Epigenome in Eukaryotic and Human Evolution" (2009) 74 Cold Spring Harb Symp Quant Biol 383 at 390.

${ }^{111}$ Sonja Langmesser \& Urs Albrecht, "Life Time - Circadian Clocks, Mitochondria and Metabolism" (2006) 23:1-2 Chronobiol Int 151; Stuart Brody, "Circadian Rhythms in Neurospora crassa: The Role of Mitochondria" (1992) 9:3 Chronobiol Int 222. 
tain serious, life-threatening illnesses typically appear in individuals with congenital or acquired mitochondrial defects. ${ }^{112}$ Given the observed associations, a general causal relationship is strongly suspected between (congenital or acquired) mitochondrial mutations and disease; however, further research is needed to confidently establish causality more broadly than in the current subset of diseases where it has been shown. ${ }^{113}$

\section{Mitochondria in the life of somatically integrated organisms}

In several ways, mitochondria appear vital to "life," at whole-organism as well as cellular levels, in human beings and other eukaryotes. First, mitochondria vastly increase the energy available to eukaryotic organisms, making possible the activities and characteristics of multicellular life. Most eukaryotes can produce only very small quantities of energy - just onesixteenth of the amount - without mitochondria, ${ }^{114}$ an amount insufficient to power the activities of complex organisms, especially neural activity. With-

112 The first identified mitochondrial disease, Luft's disease, was identified in 195962. By 1984, over 120 mitochondrial diseases were known: see Anna Gvozdjakova, "Mitochondrial Medicine" in Anna Gvozdjakova, ed, Mitochondrial Medicine: Mitochondrial Metabolism, Diseases, Diagnosis and Therapy (London, England: Springer, 2008) 103 at 103-04; Michelakis, supra note 98 at 2432-33; Arnold Y Seo et al, "New Insights into the Role of Mitochondria in Aging: Mitochondrial Dynamics and More" (2010) 123:15 J Cell Sci 2533 at 2533; Wallace, "Mitochondrial Paradigm", supra note 90 at 361; Tobias A Weber \& Andreas S Reichert, "Impaired Quality Control of Mitochondria: Aging from a New Perspective" (2010) 45:7-8 Exp Gerontol 503 at 504, 506.

${ }^{113}$ Meyer et al, supra note 102 at 2-3.

${ }^{114}$ In humans and other mammals, glycolysis allows production of very small amounts of energy anaerobically, if oxygen supplies are low. The amount of energy generated from glucose by glycolysis plus mitochondrial aerobic respiration is far greater, at 32 ATP molecules per molecule of glucose, compared with just two ATP molecules per molecule of glucose released by glycolysis alone (i.e., without the aid of mitochondria): see Denise R Ferrier, Lippincott's Illustrated Reviews: Biochemistry, 6th ed (Philadelphia: Lippincott Williams \& Wilkins, 2014) at 104, 114; EW Nester et al, Microbiology: A Human Perspective, 7th ed (Toronto: McGraw-Hill, 2012) at 134; Scott K Powers \& Edward T Howley, Exercise Physiology: Theory and Application to Fitness and Performance, 7th ed (New York: McGraw-Hill, 2001) at 43-44. Based on this figure, mitochondrial aerobic respiration provides an energy gain of $1600 \%$ over glycolysis alone. 
out the energetic gain from mitochondria, it seems likely that multicellularity would never have evolved. Certainly it has not done so in prokaryotes (bacteria), which as noted above do not have mitochondria, in the 2.5 billion years since the "endosymbiont" event, to use Lynn Sagan's terminology. ${ }^{115}$

This vast mitochondrial supply of energy fuels both cellular and wholeorganism activities. Most basically, vital homeostatic processes of cell growth, repair, and reproduction require constant energy to counteract the damaging, chaotic effects of entropy. Mitochondrial energy also makes possible other whole-organism "emergent properties" such as whole-body movement, observed in the whole body but not at the cellular level, enabling threat evasion, food-seeking, or other self-sustaining activities. Another emergent process using large amounts of mitochondrial energy is neural activity, ${ }^{116}$ which permits sensory processing, reflexes, learning, communication, and consciousness. These whole-body, emergent properties require considerable energy and would be impossible without mitochondria.

A second way that mitochondria are important to whole organisms is through their vital role in shaping specialized tissues. This occurs through the mitochondrially directed process of "apoptosis" (programmed cell death), during both embryogenesis and maintenance in later life. In multicellular organisms, tissue specialization distinguishes simple, undifferentiated cell colonies that are able to reproduce asexually by division when a colony portion separates (e.g., sponges) from true multicellular "individuals" (such as animals) whose interdependent tissues are devoted to specific functions. Such

115 See discussion in note 99, supra. Lane argues, "The efficiency of [mitochondrial] energy metabolism may have been the driving force behind the rampant ascent of eukaryotes to diversity and complexity": Lane, Power, supra note 90 at 153 . Furthermore, "[m]itochondria made larger size probable ... [and w]ith larger size came greater complexity": ibid at 187.

116 "The neural processing of information is metabolically expensive. Although the human brain is $2 \%$ of the body's weight, it accounts for $20 \%$ of its resting metabolism": David Attwell \& Simon B Laughlin, "An Energy Budget for Signaling in the Grey Matter of the Brain" (2001) 21:10 J Cereb Blood Flow Metab 1133 at 1133. Energy in the form of ATP is used in the brain to create concentration gradients between neurons and their surroundings; it is vital to their electrical activity, may be used as a neurotransmitter, and causes depolarization of neural painreceptors: Bear, Connors \& Paradiso, supra note 62 at 35, 147-48, 408. 
functions include sexual reproduction, in which the organism as a unit is reproduced using dedicated reproductive tissues.

These specialized, interdependent tissues, shaped as well as fuelled by mitochondria, together produce a kind of "somatic integration" in a living organism, synergistically creating whole-organism, emergent characteristics not seen among component cells - e.g., the coordination of muscles and nerves to allow whole-body movement. The term "integrative unity"117 is also sometimes used to describe such "somatic integration," and both terms are strongly evocative of the concept of the "organism as a whole," which the 1981 President's Commission thought definitive of biological life. Through control over tissue specialization, mitochondria permit the development, from a single-celled zygote, of multicellular "individuals" with a characteristic form, functioning as self-perpetuating, somatically integrated units. ${ }^{118}$ Long after embryogenesis, mitochondria maintain an organism's distinctive, integrated form through removal (by apoptosis) of damaged or tumorous cells that threaten the organism's structural integrity and energetic sustainability. $^{119}$

In contrast to the brain-based argument of the President's Commission, the mitochondrial function of apoptosis appears to more effectively explain the appearance of an integrated, synergistic "organism as a whole," that is, the co-operative somatic integration of cells in a living body. In this explanation, the mitochondria, and not the brain, are more likely to play a master regulator role in the body, as mitochondrial apoptosis maintains proper tissue functioning and integration. In addition, mitochondria provide the fuel for all

117 See Shewmon, “Critical Re-evaluation”, supra note 6 at 137 (defining integrative unity of an organism as the possession of at least one emergent holistic-level property).

${ }^{118}$ Some researchers think that population-level metabolic synchrony among cells of a yeast colony may derive from synchronized mitochondrial processes: see D Lloyd, EL Rossi \& MR Roussel, "Introduction: The Temporal Organization of Living Systems from Molecule to Mind" in David Lloyd \& Ernest L Rossi, eds, Ultradian Rhythms from Molecules to Mind: A New Vision of Life (Dordrecht: Springer, 2008) 1 at 4-5.

${ }^{119}$ See Lane, Power, supra note 90 at 189. For information on the process of apoptosis, see Vinay Kumar, Ramzi S Cotran \& Stanley L Robbins, Basic Pathology, 6th ed (Toronto: WB Saunders, 1997) at 13. 
bodily processes, including the energy-intensive activity of the brain, which is responsible for $20 \%$ of the body's energy expenditures despite accounting for only $2 \%$ of the body's weight. ${ }^{120}$ It seems that, even were the brain to act as a master regulator over the entire body, it is the mitochondria that fuel and enable the functions that the brain performs. Accordingly, functional mitochondria appear to exhibit a higher level of regulatory behavior and control over both body and brain.

From a mitochondrial perspective, the President's Council's emphasis on breathing as a truly important exchange between an organism and its environment, and thus as being diagnostic of life, is not without some basis. Breathing allows the body to take in oxygen for use as the final electron acceptor in the electron transport chain, enabling mitochondrial energy (ATP) production from the complete oxidation of fuel. Just as importantly, breathing expels waste carbon dioxide, avoiding an obstacle to further aerobic respiration, since high carbon dioxide levels increase dissociation of the oxygen delivery molecule, oxyhemoglobin, ${ }^{121}$ preventing sufficient oxygen delivery to cellular respiration sites. Yet from the same mitochondrial viewpoint, it is incorrect to characterize breathing as a more important exchange than nutrient ingestion. Nutrients supply the fuel molecules that are the only other vital ingredient in producing ATP via the mitochondrial electron transport chain. Thus, food ingestion is no less important - no less appetitive - than is breathing for the life of the organism as a whole. The ATP produced from both nutrients and oxygen allows a ventilated brain-dead body to do what Shewmon observed: to maintain circulation and resist disintegration, that is, to resist the forces of entropy.

3. Mitochondria and the mystery of life's oxygen-dependence

The significance of oxygen to mitochondrial energy production, and thus to the life of eukaryotic cells and whole organisms, cannot be overstated. Oxygen is vital for aerobic cellular respiration, serving as an electron acceptor in the mitochondrial respiratory chain that transforms food into energy, ${ }^{122}$

${ }^{120}$ See Attwell \& Laughlin, supra note 116 at 1133.

${ }^{121}$ See Tortora \& Derrickson, supra note 61 at 497.

122 See Powers \& Howley, supra note 114 at 37, 43. In some non-eukaryotes living in oxygen-deficient environments, a bacterial ATP-production process that is analogous to mitochondrial aerobic respiration has the flexibility to use molecules such 
although lesser amounts of energy can be produced by eukaryotes without oxygen. ${ }^{123}$ The original mitochondrial symbiosis paired an anaerobic (i.e., non-oxygen-using) host cell with an aerobic mitochondrion, allowing early eukaryotes to exploit what would otherwise have been toxic, oxygen-rich environments, but at a cost: it appears that as a result of this symbiosis, at some point in their evolution, eukaryotes became dependent on oxygen, a feature still characteristic of modern eukaryotic organisms, including humans. ${ }^{124}$ Thus, for eukaryotes, a brief period without oxygen may be lethal. As the physician Paracelsus noted in 1535, "man dies like a fire when deprived of air." 125

Without oxygen - or especially, for some reason, if oxygen flow is interrupted and then restored ${ }^{126}$ - mitochondria may become damaged and unable

as thiosulphate, sulphide, or nitrogen oxide as the final electron receptor, as well as oxygen. Since no such substitution has been reported in mitochondrial cellular respiration, oxygen seems to be essential to eukaryotes for this energy production process: see Nick Lane, Oxygen: The Molecule that Made the World (New York: Oxford University Press, 2002) at 31-32 [Lane, Oxygen].

${ }^{123}$ See note 114, supra; see also Powers \& Howley, supra note 114 at 34, 36.

${ }^{124}$ See Lane, Power, supra note 90 at 45-46:

Even if energy was not the basis of the [mitochondrion-host cell] relationship, the rise in [atmospheric] oxygen levels might still explain the initial benefits. Oxygen is toxic to anaerobic ... organisms.... If the guest [protomitochondrion] was an aerobic bacterium, using oxygen to generate its energy, while the host was an anaerobic cell (generating energy by fermentation [i.e., glycolysis]), then the aerobic bacterium may have protected its host against toxic oxygen ... [As] atmospheric oxygen levels r[o]se , the relationship beg[an] to pay dividends to both.

See also Lane, Oxygen, supra note 122 at 51.

125 Cited in Bernard Jaffe, Crucibles: The Story of Chemistry from Ancient Alchemy to Nuclear Fission, 4th ed (New York: Dover Publications, 1976) at 78.

${ }^{126}$ Interruption and re-establishment of oxygen flow is referred to as "reperfusion." The mechanism for the paradoxical phenomenon of "reperfusion injury" is emerging, including the role played by mitochondria: see e.g. Hamid Moradi \& Ping H Wang, "Renoprotective Mechanisms of Ischemic Postconditioning in IschemiaReperfusion Injury: Improved Mitochondrial Function and Integrity" (2013) 28:11 Nephrol Dial Transplant 2667; Xiaohua Tan et al, "Postconditioning Ameliorates 
to produce energy, potentially triggering cell death. Oxygen deprivation may be termed "hypoxia" (i.e., low oxygen), "anoxia" (i.e., no oxygen), or, in cases of deprivation of oxygenated blood flow, "ischemia," but the oxygen concentration denoted by these terms varies. ${ }^{127}$ Oxygen-deprivation effects seem especially severe in tissues with high energy demands, such as neural tissues. ${ }^{128}$ In mammals, a five-minute interruption of oxygenated blood may lower brain function by $90 \%,{ }^{129}$ and is associated with long-term risks of brain-cell death. In contrast, non-neural tissues such as human heart muscle may tolerate 20-30 minutes without oxygen, while certain leg muscle tissues may tolerate two to three hours' anoxia before cell death occurs. ${ }^{130}$ Even among energy-intensive neural tissues, however, some cell types are more hypoxia-sensitive than others. The more energy-intensive neurons ${ }^{131}$ (with larger mitochondrial populations) are more severely affected by ischemia

Mitochondrial DNA Damage and Deletion after Renal Ischemic Injury" (2013) 28:11 Nephrol Dial Transplant 2754.

${ }^{127}$ See Lane, Oxygen, supra note 122 at 165.

${ }^{128}$ Grey matter uses an especially large proportion of brain energy. The work done by the brain's cells is energetically equal to "human leg muscle running the marathon": Attwell \& Laughlin, supra note 116 at 1143. The brain's high energy demand may make it vulnerable to hypoxic damage.

${ }^{129}$ See Jeremy E Niven \& Simon B Laughlin, "Energy Limitation as a Selective Pressure on the Evolution of Sensory Systems" (2008) 211:11 J Exp Biol 1792 at 1794 (note that brain function was measured via the proxy of brain ATP use).

${ }^{130}$ Kumar, Cotran \& Robbins, supra note 119 at 6.

131 The metabolism of energy by the brain is "tightly coupled to neuronal activity": Renaud Jolivet, Pierre J Magistretti \& Bruno Weber, "Deciphering Neuron-Glia Compartmentalization in Cortical Energy Metabolism" (2009) 1:4 Front Neuroenergetics 1 at 1 . The authors of that study found that, during high levels of brain activity in both human and rodent data, "about $80 \%$ of energy is produced to support neuronal signaling while glia only use up a small fraction of energy to recycle neurotransmitters (5-6\%)": ibid at 2. They also observed that "a significant [proportion] of glucose is taken up by astrocytes [a form of glia] while oxygen is mostly consumed within the neuronal population," a "bias" that increases such that "the higher the activation state [of the brain], the higher the proportion of oxygen being used by neurons and the higher the proportion of glucose entering glia": ibid. 
than lower-energy glia (possessing fewer mitochondria). ${ }^{132}$ Thus, tissues differ in their needs for oxygen and mitochondrial energy, and those with greater energy requirements - and thus more mitochondria - seem to fare worse during oxygen deprivation. Emerging evidence regarding mechanisms of ischemic brain damage strongly implicates mitochondrial involvement. ${ }^{133}$

Despite the general requirement for continuous oxygen in multicellular animals, some exceptions exist. As noted above, eukaryotic cells can manufacture tiny amounts of energy without oxygen and mitochondria. For the normal activities of most vertebrates, these amounts are insufficient. Nonetheless, some vertebrates and invertebrates can, in harsh conditions, lower their metabolic needs to survive for days, months, or years with seemingly negligible oxygen and energy use, in states of daily torpor or seasonal hiber-

${ }^{132}$ Kumar, Cotran \& Robbins, supra note 119 at 717; see also O Kempski, "Mechanisms of Ischemic Cerebral Damage: The Role of Glial Cells" (1989) 1:3 J Neurosurg Anesthesiol 267 at 268-69 (glial brain cells may play a protective, homeostatic role in the brain, by swelling in ischemia, clearing away harmful substances, and buffering neurons against hypoxic damage). Rodent neurons and glia differ greatly in energy use; even at resting potential, neurons may use over three times the energy of glia, while signalling neurons use 15 times more. This energy apportionment roughly parallels the observed mitochondrial distributions among these brain cell types. Consistent with the greater glial hypoxia-tolerance, human glia need only $5 \%$ of the brain's energy and contain only $2 \%$ of its mitochondria: see Attwell \& Laughlin, supra note 116 at 1139.

${ }^{133}$ See e.g. Dennis W Choi, "Cerebral Hypoxia: Some New Approaches and Unanswered Questions" (1990) 10:8 J Neurosci 2493 at 2493 (ischemic brain damage is not due solely to an energy deficit, i.e., mitochondrial inability to produce energy without oxygen; actual cell damage is also involved); Kyungsun Choi et al, "Oxidative Stress-Induced Necrotic Cell Death via Mitochondira [sic]-Dependent Burst of Reactive Oxygen Species" (2009) 6:4 Curr Neurovas Res 213 (mitochondria may play a central role in necrotic cell death after brain ischemia or reperfusion); PG Sullivan et al, "Mitochondrial Permeability Transition in CNS Trauma: Cause or Effect of Neuronal Cell Death?” (2005) 79:1-2 J Neurosci Res 231 at 231; Seema Yousuf et al, "Resveratrol Exerts a Neuroprotective Effect by Modulating Mitochondrial Dysfunctions and Associated Cell Death in Cerebral Ischemia" (2009) 1250:1 Brain Res 242 at 242. 
nation, ${ }^{134}$ resuming normal metabolism and energy use when conditions improve.

Clearly, for an animal to be able to detect improved external conditions, arouse, and resume normal, energy-consumptive functions, some viable mitochondria must persist. In such animals, special mitochondrial adaptations have been found, including processes that prevent or reduce hypoxic mitochondrial damage. ${ }^{135}$ In addition, in contrast to the usual hypoxia-sensitivity of neural tissues, the nervous systems themselves of hypoxia-tolerant animals also seem to possess adaptations that ultimately protect mitochondria. For instance, energy-intensive neural functions such as consciousness may be greatly reduced, allowing these organisms to hibernate during hypoxic periods. ${ }^{136}$ While humans cannot survive hypoxia by hibernating, similarly unresponsive neurological states do occur in humans affected by hypother-

${ }^{134}$ It seems that animals adapted to survive anoxia or cold in this way (e.g., turtles) may greatly limit their mitochondrial consumption of ATP and increase their dependence on non-mitochondrial energy production through glycolysis, thereby matching the low ATP supply (available mainly from the latter process): see PW Hochachka \& PL Lutz, "Mechanism, Origin, and Evolution of Anoxia Tolerance in Animals" (2001) 130:4 Comp Biochem Physiol B Biochem Mol Biol 435 at $439,442,451$. A possibly related phenomenon in humans subjected to cold or other abnormal conditions is noted later.

${ }^{135}$ For example, in animals that tolerate lengthy hypoxia (such as turtles under winter ice), permanently reduced mitochondrial membrane permeability and reversible blocking of mitochondrial membrane pores may occur, and tissue mitochondrial populations may be reduced during dormancy: ibid at 437, 439, 447. See also Matthew T Andrews, "Advances in Molecular Biology of Hibernation in Mammals" (2007) 29:5 BioEssays 431 at 432 (mitochondria are implicated in hibernation strategies to survive non-anoxic energy-depletion as mitochondrial enzyme PDK4 blocks glycolysis, preventing mitochondrial ATP production and decreasing metabolism); Stephen C Land, "Hochachka's 'Hypoxia Defense Strategies' and the Development of the Pathway for Oxygen" (2004) 139:3 Comp Biochem Physiol B Biochem Mol Biol 415 (in the human fetus, too, hypoxia-resistance involves reduced mitochondrial biogenesis and energy production).

136 Niven \& Laughlin, supra note 129 at 1794. Drastic (i.e., ten-fold) reductions may occur in hibernating vertebrates' neural firing, reducing energy use in anoxic conditions: see Hochachka \& Lutz, supra note 134 at 437. 
mia, ${ }^{137}$ certain drugs, ${ }^{138}$ exsanguination, or other conditions, with brain, heart, and lung functions becoming imperceptible. Due to the ethical difficulties of experimentation, these states are not well understood in humans.

In organisms lacking such adaptations, hypoxia initiates a predictable sequence of cellular damage, centrally affecting the mitochondria. This begins with significant decreases in mitochondrial respiration, reducing intracellular ATP production. ${ }^{139}$ After short hypoxic episodes, reversible changes occur, ${ }^{140}$ including phospholipid deposition in the mitochondria (suggesting mitochondrial membrane degradation) and mitochondrial swelling (suggesting loss of osmotic regulation by mitochondrial membranes). Longer hypoxia produces worsening energy production and increased membrane permeability, which can lead to additional morphological deterioration. ${ }^{141}$ Empirically, after extended hypoxia, a "point of no return" is reached, such that "mitochondrial dysfunction cannot be reversed and irreversible damage and cell death occur" even when oxygen is restored. ${ }^{142}$

${ }^{137}$ Cold is a well-known confounding variable in brain death determination. In hypothermia, human beings with core temperatures below $32^{\circ}$ Celsius may enter a reversible state mimicking brain death, becoming temporarily unconscious, neurologically unresponsive, and exhibiting no apparent breathing, brain stem reflexes, or other life signs: see Eelco FM Wijdicks, "Determining Brain Death in Adults" (1995) 45:5 Neurology 1003 at 1004; Ad Hoc Committee of the Harvard Medical School to Examine the Definition of Brain Death, "A Definition of Irreversible Coma" (1968) 205:6 JAMA 337 at 338, 340.

${ }^{138}$ As noted earlier, barbiturates may reversibly produce symptoms resembling brain death, including central nervous system depression, respiratory depression, lowered cardiac output, and poor temperature regulation: see RM Schears, "Barbiturates" in Judith Tintinalli et al, eds, Tintinallis Emergency Medicine: A Comprehensive Study Guide,(New York: McGraw-Hill, 2011) at Clinical Features, Treatment sections.

${ }^{139}$ Kumar, Cotran \& Robbins, supra note 119 ("[t]he first effect of hypoxia is on the cell's aerobic respiration ... by mitochondria; as a consequence of reduced oxygen tension, the intracellular generation of ATP is markedly reduced ... [with] widespread effects on many systems within the cell" at 6).

${ }^{140}$ Ibid at 7.

${ }^{141}$ Ibid at 8.

142 Ibid. 
While the characteristics of this "point of no return" are still emerging, they appear to be triggered by cellular $\mathrm{pH}$ and ATP changes, producing irreversible mitochondrial swelling and cellular calcium influx. ${ }^{143}$ Oxygen reperfusion (i.e., reintroduction of oxygen) is particularly damaging in this context because it opens a mitochondrial membrane pore, making the inner mitochondrial membrane permeable and triggering the membrane protein ATP synthase to operate in reverse, consuming energy instead of creating it. ${ }^{144}$ Calcium coalesces in the mitochondrial matrix, especially if oxygen is restored, ${ }^{145}$ which may physically obstruct further cellular respiration. However, simply interrupting mitochondrial energy production does not always appear to be sufficient by itself to trigger cell death. ${ }^{146}$ Instead - whether or not oxygen is restored - when cell death ensues, it is preceded by a burst of oxygen free radicals that is damaging to mitochondrial membranes and DNA. This free radical burst appears to be a mitochondrial signal triggering the host cell to begin enzymatic self-destruction, a process that was perhaps once a mechanism permitting an ancestral mitochondrion to escape to a new host cell. ${ }^{147}$

${ }^{143}$ See Gvozdjakova, "Mitochondrial Physiology", supra note 95 (at this point, "excessive accumulation of $\mathrm{Ca}^{2+}$ leads to formation of [oxygen free radicals] and opening of the mitochondrial transition permeability pore (MPTP), which depolarizes the mitochondria[1] [membrane] and leads to mitochondrial swelling" at 16).

144 Roberta A Gottlieb \& Raquel S Carreira, "Autophagy in Health and Disease. 5. Mitophagy as a Way of Life" (2010) 299:2 Am J Physiol Cell Physiol C203 at C205.

${ }^{145}$ It is unclear why oxygen restoration has such severe negative effects. More free radicals may be released in tissues with partial (reperfused) oxygen than with no oxygen: see Choi, supra note 133 at 2497 . Oxygen restoration may increase intracellular $\mathrm{pH}$ following acidic conditions (produced by the lack of aerobic respiration), opening the mitochondrial membrane pore, triggering mitochondrial swelling and other damage: see JJ Lemasters et al, "The Mitochondrial Permeability Transition in Cell Death: A Common Mechanism in Necrosis, Apoptosis and Autophagy" (1998) 1366:1-2 Biochim Biophys Acta 177 at 178 [Lemasters et al, "Mitochondrial Permeability Transition"].

${ }^{146}$ See Kumar, Cotran \& Robbins, supra note 119 ("it has been possible experimentally to dissociate ... ATP depletion, from the inevitability of cell death" at 8).

147 The free radical burst occurs when respiration in mitochondrial electron transport chains is interrupted, as stalled electrons release free radicals, possibly because oxygen is suddenly unavailable as an acceptor for respiratory chain electrons: see 


\section{Mitochondria in the pathways of cell death}

In general, cell death is triggered in two ways, both of which centrally involve mitochondria: (1) events external to the cell (e.g., hypoxia) may trigger the process of "necrosis," and (2) internal cellular events may trigger "apoptosis" (i.e., internally programmed cell death). ${ }^{148}$ Apoptosis may allow cells with mitochondria too damaged to produce energy to be removed and replaced by cells with viable mitochondria. ${ }^{149}$ In apoptosis, the damaged cell

Lane, Power, supra note 90 at 222, 260. The enzymes used in the ensuing cell destruction appear to have bacterial genetic origins and are similar to those used by modern bacterial parasites escaping dying host cells: see ibid at 212-13; Braschi \& McBride, supra note 104 at 961. Although mitochondria of fully differentiated host cells also break down, rather than escape and transfer to new hosts, mitochondria have been observed to transfer into damaged stem cells, restoring their functionality: see Nesti et al, supra note 109 at 168.

${ }^{148}$ In necrosis and apoptosis, mitochondria and the ATP they produce play key roles. A key step in both involves the opening of a pore in the inner mitochondrial membrane (the "mitochondrial permeability transition pore" or MPTP). In both necrosis and apoptosis, when oxygen is disrupted, then re-established, the return to normal (higher) $\mathrm{pH}$ triggers pore opening, allowing in water and calcium, causing mitochondrial swelling and cytochrome $\mathrm{c}$ release. This interrupts respiration and triggers cell death, either immediately (via necrosis) or later (via apoptosis). MPTP opening makes the inner mitochondrial membrane permeable and forces the membrane protein ATP synthase to operate in reverse, consuming ATP. See Gottlieb \& Carreira, supra note 144 at C205. Cellular ATP levels seem to determine which cell death process occurs: if cellular ATP levels are low, rapid cell necrosis occurs, while if ATP levels are higher, apoptosis occurs later: see Lemasters et al, "Mitochondrial Permeability Transition", supra note 145 at 177; JJ Lemasters et al, "Mitochondrial Dysfunction in the Pathogenesis of Necrotic and Apoptotic Cell Death" (1999) 31:4 J Bioenerg Biomembr 305. Opening of the MPTP pore can be partially blocked by some drugs, such as the transplant anti-rejection drug cyclosporine A, or by $\mathrm{pH}$ below 7.4, thereby protecting the mitochondrion from damage: see Jae-Sun Kim et al, "Nitric Oxide: A Signaling Molecule Against Mitochondrial Permeability Transition- and pH-Dependent Cell Death after Reperfusion" (2004) 37:12 Free Radic Biol Med 1943 at 1944; J-S Kim et al, "Role of the Mitochondrial Permeability Transition in Apoptotic and Necrotic Death after Ischemia/Reperfusion Injury to Hepatocytes" (2003) 3:6 Cur Mol Med 527 at 527.

${ }^{149}$ Lane speculates "that any cells that acquir[e] an unworkable load of [mtDNA] mutations [a]re simply eliminated by apoptosis, giving an impression that mitochondrial mutations $\mathrm{d}[\mathrm{o}]$ not accumulate with age," due to the remaining cells with less severely damaged mitochondria continuing to divide: Lane, Power, supra note 90 
is destroyed from within by the enzyme caspase 3, which digests the cell, mitochondria, and other cell contents. ${ }^{150}$ In contrast, cell death by necrosis occurs more rapidly than by apoptosis, and is triggered by more severe cell damage. ${ }^{151}$ While it was once thought that the mitochondrial damage seen in necrosis occurred secondarily to cell damage, evidence now indicates the reverse: that in necrosis, mitochondrial damage is primary, itself triggering cellular destruction. ${ }^{152}$ In summary, apoptosis and necrosis share common pathways, both triggered by mitochondrial damage. ${ }^{153}$ Thus, in addition to facilitating and controlling eukaryotic cellular life, mitochondria appear to direct eukaryotic processes of cellular death.

at 300 . The same may be true of necrosis in more severely damaged cells, over the short-term.

${ }^{150}$ Ibid at 207, 209.

${ }^{151}$ For example, in pancreatic cells, a shorter or less intense chemical insult was observed to produce apoptosis, while a lengthier or more intense insult led more rapidly to necrosis: see Jeanette M Dypbukt et al, "Different Prooxidant Levels Stimulate Growth, Trigger Apoptosis, or Produce Necrosis of Insulin-Secreting RINm5F Cells: The Role of Intracellular Polyamines" (1994) 269:48 J Biol Chem 30553 at 30557, 30559-60.

${ }^{152}$ See BK Siesjö et al, "Role and Mechanisms of Secondary Mitochondrial Failure" (1999) 73:1 Acta Neurochir Suppl 7.

${ }^{153}$ Necrosis may result when cellular ATP stays high in a hypoxia-damaged cell; apoptosis may result when cellular ATP in a hypoxia-damaged cell is low: see Gvozdjakova, "Mitochrondrial Physiology", supra note 95 at 16. Thus mitochondria may be energy sensors as well as energy producers, monitoring cellular ATP supplies and triggering changes via apoptosis or mitochondrial biogenesis when cells fail to meet some bioenergetic threshold: see Lane, Power, supra note 90 at 293. The mitochondrial protein cytochrome $\mathrm{c}$ that stops chemical respiration and activates caspase 3, triggering cell apoptosis or necrosis, is noteworthy for its symmetric role in cellular life and death. "[A]n integral component of the respiratory chain (which generates the energy needed for the life of the cell) turns out to be an integral component ... responsible for the death of the cell. The link between life and death hinges on the subcellular location of a single molecule": ibid at 209. 
5. Mitochondria in the aging and death of the organism as a whole

Mitochondrial involvement in death does not appear to stop at the cellular level. In healthy human beings, 10 billion cells die daily ${ }^{154}$ without producing functional deficits at the organism level. Cells of the human body are regularly replaced. ${ }^{155}$ There exists a "dynamic equilibrium" in multicellular organisms whereby dying or dead cells ${ }^{156}$ are continuously replenished by new cells. In good health, most cells of each tissue remain alive, thereby permitting vital emergent processes of the living organism. However, at some point, if the cell death rate exceeds the dynamic equilibrium replacement rate, this may precipitate the death of the entire organism through means such as widespread systemic infection or vital organ failure. Arguing that brain death triggers the death of the organism as a whole, Bernat stated that "[ $t]$ he irretrievable loss of the organism's emergent functions ... is the death of the organism." 157 Given this causal chain, our preceding discussion prompts us to consider whether mitochondria appear centrally implicated in the death not merely of cells, but of the "organism as a whole."

As noted, some organisms (including humans under certain conditions) can survive reversible, death-mimicking states, wherein emergent functions -

${ }^{154}$ Ibid at 215.

${ }^{155}$ Cells of the human body are replaced at different rates, with skin cells lasting just five days, while other cells may be replaced much less frequently: see Nicholas Wade, "Your body is younger than you think", New York Times (2 August 2005) online: NYT <www.nytimes.com/2005/08/02/science/02cell.html?pagewanted $=$ all $>$.

${ }^{156}$ Certain body parts of living multicellular organisms may be "dead" or "inanimate," e.g., hair, nails, the mineral portions of bones or teeth, a shell, furry coat, or feathers. Conversely, organisms resident on or in a living organism's body may contribute to its overall life and health through protective, structural, or homeostatic functions. For instance, in addition to the mitochondria in each human cell, beneficial and parasitic bacterial and fungal "flora" inhabit the human skin, oral cavity, intestinal tract, and other body parts in a ratio of ten non-human cells to one human cell: see Science News, "Humans have ten times more bacteria than human cells: how do microbial communities affect human health?" Science Daily (5 June 2008), online: SD <www.sciencedaily.com/releases/2008/06/080603085 914.htm>. Such features may make the human body more like a miniature ecosystem than a single entity.

${ }^{157}$ Bernat, "Whole-Brain Optimum", supra note 23 at 38 [emphasis added]. 
e.g., detectible neural activity - disappear temporarily. Thus, while the disappearance of emergent functions is necessary for an organism's death, it is not sufficient to establish death. Something more is needed to render the disappearance of emergent functions permanent, thereby explaining death's permanence and irreversibility. Death appears to require some irreparable ${ }^{158}$ destruction of vital structures or processes, making resumption of emergent functions impossible. As demonstrated above, mitochondria appear vital to generating emergent life functions of whole organisms, and therefore, one might suspect that mitochondria may also be the key structures involved in the "irretrievable loss" of these same emergent functions, i.e., death. Based on the discussion of mitochondria so far, the physical death of an organism might be predicted to occur when mitochondria become damaged beyond their self-repair or replacement capacities.

Research into aging supports this view. Mitochondria appear to play an important role in age-related decline, ${ }^{159}$ ultimately leading to the death of whole organisms. It is now widely believed that increasing mitochondrial mutation levels, rising free radical production, and declining ATP production

158 "Irreparable" in this context means unable to be repaired naturally by the body or by existing (or imminently available) medical technology.

${ }^{159}$ For the origin of this theory, see Denham Harman, "The Biologic Clock: The Mitochondria?" (1972) 20:4 J Am Geriatr Soc 145 (Harman's "mitochondrial theory of aging" argued that aging is due to accumulated mitochondrial mutations caused by oxygen free radicals). Modern speculation is that a more dynamic "quality control" relationship may exist between host cell and mitochondrion. In this view, mitochondria monitor dysfunction in cellular energy production and correct it (via cell death and replacement), until dysfunctional cells become so numerous that correction is no longer possible, due to the proportion of mutant mitochondria: see Lane, Power, supra note 90 at 274, 288, 300; Gilad Twig, Brigham Hyde \& Orian S Shirihai, "Mitochondrial Fusion, Fission and Autophagy as a Quality Control Axis: The Bioenergetic View" (2008) 1777:9 Biochim Biophys Acta 1092 at 1092; Seo et al, supra note 112 at 2533; Weber \& Reichert, supra note 112 at 503. Mitochondrial mutations can cause traits of aging, such as osteoporosis, hair loss, lower fertility, and heart enlargement: see Mügen Terzioglu \& Nils-Göran Larsson, "Mitochondrial Dysfunction in Mammalian Ageing" in Derek J Chadwick \& Jamie Goode, eds, Mitochondrial Biology: New Perspectives (London, UK: John Wiley \& Sons, 2007) 197 at 203. Chronic degenerative diseases of aging linked to mitochondrial abnormalities include diabetes, congestive heart disease, cancer, and Alzheimer's: see Shokolenko, Ledoux \& Wilson, supra note 101 at 330-31. 
in an organism may cause or contribute to aging. ${ }^{160}$ Mitochondria may function as a "biological clock," 161 dictating organisms' life expectancy. ${ }^{162}$ The mechanism for this mitochondrial biological clock may involve the greater possibly as much as twenty-fold greater - mutation-susceptibility of mito-

${ }^{160}$ See Yau-Huei Wei et al, "Respiratory Function Decline and DNA Mutation in Mitochondria, Oxidative Stress and Altered Gene Expression during Aging” (2009) 32:2 Chang Gung Med J 113; Gredilla, Bohr \& Stevnsner, supra note 103 at 478, 484-85. Significantly, mutated mitochondria may be preferentially reproduced over normal mitochondria within host cells, possibly in compensation for the low energy production of mutated mitochondria: see Wallace, "Mitochondrial Paradigm", supra note 90 at 366-67.

161 There is much speculation over the inevitability of eukaryotic aging and death, and why natural selection has not removed these phenomena from the gene pool. Controversially, some suggest that aging and death offer advantages (to species) by making room for new individuals and improving species overall: see Randolph M Nesse \& George C Williams, Why We Get Sick: The New Science of Darwinian Medicine (New York: Vintage Books, 1996) at 109. As Lane explains, in essence “ageing [and death] doesn't seem to benefit the individual ... but does look like a useful service to the species, for it leads to population turnover, preventing overcrowding and over-consumption of lean resources": Lane, Power, supra note 90 at 191 [emphasis added]. Yet natural selection is theorized to act upon individuals, not groups (except possibly kin): ibid at 191-92. Thus, an alternative view, possibly more consistent with mitochondrial science, is that aging is a "dust-bin of lateacting mutations" which natural selection cannot eliminate due to the mutations' post-reproductive onset: see Nesse \& Williams, supra note 161 at 113-14, citing JBS Haldane, New Paths in Genetics (New York: Harper, 1942) and PB Medawar, "Old Age and Natural Death" in PB Medawar, ed, The Uniqueness of the Individual (London, UK: Methuen, 1957) 17 at 38.

${ }^{162}$ Nesse \& Williams, supra note 161 at 108 ("life expectancy" is the maximum age an individual of a species may attain, while "life span" is the average age an individual of that species attains). More efficient mitochondria are associated with a longer life in some animals. Lower free radical damage (by more efficient mitochondria) is linked to longer life expectancy in laboratory mammals: see Gredilla, Bohr \& Stevnsner, supra note 103 at 484 . Conversely, birds tend to have more efficient mitochondria and correspondingly long lifespans: see Lane, Power, supra note 90 at 269, 308. Experimental animal research has also demonstrated that congenital mtDNA mutations can exacerbate phenotypic signs of aging: see Jaime M Ross et al, "Germline Mitochondrial DNA Mutations Aggravate Ageing and Can Impair Brain Development” (2013) 501:7467 Nature 412 at 412. 
chondrial DNA than nuclear DNA. ${ }^{163}$ This vulnerability may be due to the physical proximity of mitochondrial DNA to the electron transport chain, which continuously leaks low levels of damaging free radicals, an arrangement that might be likened to a mitochondrion's keeping its genetic blueprint too near its own internal "incinerator." 164 Other features of mitochondrial DNA leave it unprotected and less easily repaired than nuclear DNA. ${ }^{165}$

${ }^{163}$ See Lane, Power, supra note 90 at 245; see also Shokolenko, Ledoux \& Wilson, supra note 101 at 330 (giving a figure of a ten-fold greater rate of mutation). The precise mitochondrial mutation rate is difficult to assess, since the observed rate represents the result after natural selection: Lane, Power, supra note 90 at 245, $260,285-86$. The high mitochondrial mutation rate raises the question why all mitochondrial genes were not transferred to the nuclear genome, which is better protected from damage. The reason may be that mitochondrial retention of some genes may enable a more rapid response to changing oxygen levels: see Lane, $O x$ ygen, supra note 122 at 265-66, n 7.

${ }^{164}$ Douglas C Wallace, founding Director of the Center for Molecular and Mitochondrial Medicine and Genetics, University of California at Irvine, likens mtDNA to the genetic blueprint for a house's electrical wiring. He explains in lay terms, "The mitochondria are unique because they have their own DNA (labeled mtDNA) and that DNA is the blueprint to determine how energy is generated and used. So, as we age in the process of making energy, the mitochondria also make ... oxygen radicals. The oxygen radicals are just like smoke; they will damage their environment.... The mitochondria [are] constantly struggling between the process that is making energy, which makes the smoke, and the smoke, which intoxicates the cell. The consequence is that the cell then has to use the information in its [mt]DNA to repair this damage": Interview of Douglas C Wallace, "Mitochondria and Aging" (March 2008) on Action Bioscience - American Institute of Biological Sciences, online: ABS: <www.actionbioscience.org/genomics/wallace.html> [Wallace Interview]. See also Lane, Power, supra note 90 at 279-80. An alternative view suggests that, rather than being a passive "incinerator," the mitochondrion's role may be more as an active energy-monitoring system: see Braschi \& McBride, supra note 104 at 959 .

${ }^{165}$ Meyer et al explain, "mtDNA is more vulnerable than nDNA [nuclear DNA] to some environmental genotoxins although the opposite is also true in some cases ... A number of explanations for this observation have been presented, including mtDNA's physical location [near the electron transport system], its reduced protein packaging compared with nDNA, and its reduced repair capacity": supra note 102 at 5. Meyer et al acknowledge some (partial) protective effect of the high mtDNA copy number and of certain proteins that associate with mtDNA, reducing its vulnerability to reactive chemicals, but emphasize that: 
Therefore, over time, it appears mutations may accumulate faster in mitochondrial DNA than in host DNA. ${ }^{166}$ As old mitochondria divide to produce new mitochondria, these mutations are duplicated in subsequent daughter mitochondria, reducing their energy production and eventually triggering apoptosis of affected cells. Normally, this allows surviving, healthy cells to repopulate the tissue in a self-correcting manner. However, as a selfcorrecting system, apoptosis does not appear to keep pace with the mitochondrial mutation rate, so mutations accumulate and a "vicious cycle" 167 of reduced energy production and increased apoptosis intensifies over time:

In ageing cells, mitochondrial genes accumulate new mutations.... [Mitochondrial $r$ ] espiratory function declines, freeradical leakage rises, ... the mitochondria begin to promote apoptosis[,] ... energy diminishes, we become far more vulnerable to all kinds of diseases, and our organs shrink and wither.... [Thus] mitochondria are central not only to the beginning of our lives, but also to their end. ${ }^{168}$

[a] very large difference between nDNA and mtDNA is the relative lack of repair pathways present in the mitochondria, at least in humans ... [with] many types of damage [being] irreparable or only very slowly repaired. Base excision repair is present in mitochondria, but nucleotide repair ... is not, and recombinational and mismatch repairs are either absent or quite limited ... The sole replicative mtDNA polymerase, DNA polymerase $\gamma$, appears to have very little translesion synthesis capacity ..., so that this damage tolerance mechanism is also lacking or very limited [ibid at 6].

166 This would appear to follow from the combined effects of a faster mtDNA mutation rate as compared to nDNA and a lesser mtDNA repair capacity than in nDNA.

167 Age-related diseases leading to death demonstrate a positive feedback loop ("vicious cycle" or "self-reinforcing spiral"): see Seo et al, supra note 112 at 2533; Mary-Ellen Harper et al, "Ageing, Oxidative Stress and Mitochondrial Uncoupling” (2004) 182:4 Acta Physiol Scand 321 at 321. Conversely, in life, mitochondrial "quality control" mechanisms (autophagy removing damaged mitochondria) permit the opposite pattern, i.e., a negative feedback loop, whereby mitochondria maintain high energy production, despite mutations, as long as possible: see Braschi \& McBride, supra note 104 at 959; Gottlieb \& Carreira, supra note 144 at 203; Twig, Hyde \& Shirihai, supra note 159 at 1092.

${ }^{168}$ Lane, Power, supra note 90 at 265. 
Since new mitochondria can only form from pre-existing mitochondria, ${ }^{169}$ in old age, when many mitochondria in tissues contain mutations, fewer healthy templates exist for future mitochondrial generations. Possibly as a result, according to an empirically observed phenomenon termed the "Hayflick Limit," normal cells can only undergo a fixed, species-specific number of divisions during an organism's lifespan. ${ }^{170}$

Irreversibility has long been considered an essential aspect of death by philosophers, physicians, and laymen alike. Yet such "irreversibility" may have many possible definitions. Stuart Youngner and colleagues cite three possible interpretations of the term (from strongest to weakest), which they attribute to David Cole:

1. "[The] lost function cannot be restored by anyone under any circumstances at any time now or future."

2. "[The] loss of function cannot be reversed by those [means or individuals] present at this time."

3. "[The] function is irreversibly lost if a morally defensible decision has been made not to try to reverse the loss."171

${ }^{169}$ Ibid at 195.

${ }^{170}$ Lane, Oxygen, supra note 122 at 267-68. As Lane indicates (ibid), different cell types possess different Hayflick limits, with the cells of short-lived species usually possessing lower limits; for instance, human fibroblast cells are capable of 50 to 70 divisions, whereas mouse fibroblast cells can divide only 15 times. Cancer cells are an exception: they appear to have no Hayflick limit and divide indefinitely. Notably, Lane observes, cancer cells tend to operate on anaerobic respiration and have low levels of (functional) mitochondria, rendering the problem of mitochondrial mutation moot: ibid at 273.

171 Stuart J Youngner, Robert M Arnold \& Michael A DeVita, "When is 'Dead'?" (1999) 29:6 Hastings Cent Rep 14 at 16, citing David Cole, "Statutory Definitions of Death and the Management of Terminally Ill Patients Who May Become Organ Donors after Death" (1993) 3:2 Kennedy Inst Ethics J 145 [emphasis added]. Note that while interpretations 1 and 2 are taken by Youngner, Arnold \& DeVita verbatim from Cole, the third does not in fact appear as such in Cole's paper, but rather emerges indirectly from his criticism of the University of Pittsburgh Medical Center's policy on organ removal ("the UPMC protocol countenances pronouncing as dead persons who may well have sufficient CNS function to permit resuscitation, and the protocol sees this interpretation of statutory definitions of death as satisfy- 
Jeff McMahan argues that only in the first case is an organism actually dead in the commonly accepted sense. In the second case, he argues, "[i]f an organism stops functioning but its function could be recovered by means of a device that we do not in fact possess, it is not dead."172 This view has been taken up by others, as discussed below. Regarding the third case above, McMahan argues that a human decision not to revive an organism - for example, not to replace its lost function technologically - does not equate to the irreversibility of death in the usual, accepted sense. If a lost human function can be repaired or replaced with existing technology, but will not be for moral, social, or legal reasons (a "do not resuscitate" order, for example), such a decision should not be conflated with a conclusion that a biologically irreversible change in its life status has occurred.

In the spirit of the second definition of irreversibility, "transhumanists" such as Ray Kurzweil, Richard Feynman, and James Hughes argue that conquering aging and death is purely a matter of time, technological capacity, and human willpower, a feat they believe will someday be accomplished. ${ }^{173}$

ing the requirement that the cessation of cardiopulmonary function is irreversible": Cole, ibid, at 148 [emphasis in original]).

172 Jeff McMahan, “An Alternative to Brain Death" (2006) 34:1 JL Med \& Ethics 44 at 45 .

${ }^{173}$ Kurzweil argues that the ideas of life as finite and death as inevitable are so deeply ingrained that we continue to rationalize death's necessity instead of focusing on its reversal: supra note 18 at 326. Similarly, nanotechnology founder Richard Feynman views death as a disease, rather than as an inevitable biological endpoint: "[T]here is nothing in biology yet found that indicates the inevitability of death. This suggests to me that it is not inevitable at all and that it is only a matter of time before biologists discover what is causing us the trouble and this terrible universal disease ... will be cured": Richard P Feynman, "What Is and What Should Be the Role of Scientific Culture in Modern Society" in Jeffrey Robbins, ed, The Pleasure of Finding Things Out: The Best Short Works of Richard P Feynman (Cambridge, Mass: Perseus Books, 1999) 97 at 100. James Hughes thinks that cryonic suspension and nanotechnology will increase the longevity of human bodies, but looks toward a time when, like computer files that can be backed up and preserved and/or merged with others, human physical boundaries will vanish and "perhaps we will also then be beyond death": James J Hughes, "The Death of Death" in Calixto Machado \& D Alan Shewmon, eds, Advances in Experimental Medicine and Biology, vol 550: Brain Death and Disorders of Consciousness (New York: Springer Science+Business Media, 2004) 79 at 81-82, 85. 
Theoretical support exists for this view. Technological replacements for lost functions, e.g., heart-lung bypass machines, now prolong human life where death would once have seemed inevitable. It may one day be possible to isolate or engineer mitochondrial-protectant drugs, based on observations of hypoxia-tolerant species. Genetic engineering may also offer some potential to repair mitochondrial mutations. ${ }^{174}$ For instance, placing mitochondrial genes into the host nucleus might better protect mitochondria against agerelated free radical damage and mutation, by removing the mitochondrion's genetic blueprint from the "incinerator" where oxygen free radicals are generated. ${ }^{175}$

Yet these are currently distant possibilities. ${ }^{176}$ Mitochondria have resisted efforts to culture and replace them. ${ }^{177}$ Their "alien" nature - as organisms of a distant biological relationship to our animal cells - and their highly complex and poorly understood symbiotic relationship with host cells seem likely to challenge technological manipulation for some time to come. Given the complexity of the mitochondrial symbiosis and our rudimentary understanding of it, new treatments may have unforeseen negative consequences, such as the significant fatigue and reduced exercise tolerance suffered by users of cyclosporine A, a mitochondrial-protectant drug whose side effects appear to result from the suppression of mitochondrial energy production. ${ }^{178}$ The po-

${ }^{174}$ See Eric A Schon et al, "Therapeutic Prospects for Mitochondrial Disease" (2010) 16:6 Trends Mol Med 268; DS Kyriakouli et al, "Progress and Prospects: Gene Therapy for Mitochondrial DNA Disease" (2008) 15:14 Gene Ther 1017; K Irwin, News Release, "UCLA scientists find a way to repair mutations in human mitochondria" (12 March 2012), online: UCLA <www.newsroom.ucla.edu/portal/ ucla/ucla-scientist-find-way-to-repair-230241.aspx>.

${ }^{175}$ Mauro Scarpelli et al, "Current Options in the Treatment of Mitochondrial Diseases" (2010) 5:3 Recent Pat CNS Drug Discov 203 at 203.

${ }^{176}$ As Wallace explains, "Right now, we cannot manipulate mtDNA in the same ways that people can manipulate the nuclear DNA; it is in a very different part of the cell, in a very different environment. So the same tools can't be used": Wallace Interview, supra note 164.

${ }^{177}$ Lane, Power, supra note 90 at 16.

${ }^{178}$ Cyclosporine A protects mitochondria somewhat against hypoxic damage by preventing opening of the mitochondrial permeability transition pore: see Eloisa Arbustini \& Jagat Narula, "Cyclosporin A in Reperfusion Injury: Not Opening to Cell Death Knocking at the Door?” (2010) 89:5 Ann Thorac Surg 1349. Yet cyclospor- 
tential for effects on a vital symbiosis suggests that any treatments affecting or directly targeting mitochondria must be explored with caution.

At present, no known way exists by which to "turn back the clock" on mitochondrial aging and death. ${ }^{179}$ When a threshold mitochondrial mutation rate is reached, causing energy production to be significantly reduced, it presumably follows that breathing or circulation will cease due to infection, injury, organ failure, or other causes. As described above, once a sustained cessation of oxygenated blood occurs, mitochondria are irreversibly damaged, with calcium deposits preventing future energy production and releasing the free radical signal for enzymatic cell destruction. This destruction will occur first in hypoxia-sensitive tissues (e.g., the cortex of the brain, and later the brain stem and the heart) and subsequently in more hypoxiaresistant tissues. Without viable mitochondria, the cessation of energy production becomes permanent, and without energy, the body can neither sustain emergent functions nor resist entropy. The cells of the body begin to self-destruct en masse, and their component molecules are dispersed into the inanimate environment or taken up by other life forms as nutrients. ${ }^{180}$ Thus, the death of the "organism as a whole" occurs and cannot be reversed.

A body-centred, mitochondrial mechanism for biological death can explain all of death's common features, ${ }^{181}$ with death being an unfortunate side

ine A's side effects may reduce mitochondrial energy production in skeletal muscle, causing significant fatigue and reduced exercise tolerance: see James $\mathrm{F}$ Hokanson, Jacques G Mercier \& George A Brooks, "Cyclosporine A Decreases Rat Skeletal Muscle Mitochondrial Respiration in vitro" (1995) 151:6 Am J Respir Crit Care Med 1848 at 1848.

${ }^{179}$ However, caloric restriction and/or regular aerobic exercise may slow the "ticking" of the mitochondrial clock, by lowering free radical production: see Michelakis, supra note 98 at 2432; Wallace, "Mitochondrial Paradigm", supra note 90 at 365; Saris \& Heymsfield, supra note 105 at 663.

${ }^{180}$ After death, body parts may be ingested by predators, scavengers, or decomposing organisms, such that the normal microbial body "flora" present during life are replaced by other microbes associated with decay.

${ }^{181}$ Some question whether "death" is the same process for organisms that reproduce asexually, by division: see e.g. McMahan, supra note 172 at 44. Bernat has argued that there may be differences in the biological death process between the deaths of vertebrate and invertebrate animals, e.g., planaria (flatworms): see James Bernat, “Are Brain-Dead Patients Really Dead?" (Lecture delivered at the Brain Matters: 
effect of the eukaryotic dependence on mitochondrial energy. This dependence may be stricter in complex, specialized organisms (e.g., humans) performing high-energy activities than in simpler eukaryotic organisms (e.g., yeast) whose less sophisticated activities can be fuelled even with a $94 \%$ drop in energy supply. Death's universality and similarity among multicellular eukaryotes are both explained by the fact that mitochondria are a universal feature of all free-living (non-parasitic) eukaryotes, ${ }^{182}$ performing the same functions in all of them that permit emergent properties. In animals, a mitochondrial role explains life's oxygen-dependence and the temporal link between death and the lost circulation of oxygenated blood. ${ }^{183}$

Death's inevitability and link with aging are also explained by the mitochondrial "biological clock" function, which accumulates mutations faster than apoptosis can eliminate them. The irreversibility of death reflects the body's inability to create new functional mitochondria when template mitochondria are damaged, coupled with our present technical inability to repair, culture, and replace mitochondria. Finally, death's temporal association with disintegration and decay results from the loss of mitochondrial energy, without which the body cannot resist entropy and disintegration. This may also explain why the same physical matter is present immediately before and after death, yet afterwards the body seems to lack some "animating spark" - the energy produced by mitochondria.

New Directions in Neuroethics Conference, Halifax, NS, 26 September 2009) [unpublished]. Based on a mitochondrial mechanism, death should occur via the same mechanism for all eukaryotes - i.e., irreversible mitochondrial damage leading to cell, tissue, and whole-organism death - but in animals that reproduce (in part) by division, the question of when death occurs is complicated by the fact that a portion of the original individual may persist, still functioning, in subsequent "daughter" organisms; in this particular respect they are similar to prokaryotic organisms.

182 The exception to this otherwise universal rule is certain eukaryotic parasites, all of which descend from ancestors with mitochondria: see Lane, Power, supra note 90 at 17, 51; see also ibid at 46-48. These exceptional eukaryotes appear to have lost their mitochondria over time, perhaps finding it more efficient to rely on host ATP supplies.

${ }^{183}$ However, blood circulation need not be maintained by natural cardiopulmonary means. For instance, isolated heads have been maintained "alive" (i.e., exhibiting tissue viability and emergent properties) using artificial re-oxygenation and circulation of blood by heart-lung machine: see Pernick, supra note 35 at 5 . 


\section{Mitochondrial Viability in the Brain-Dead Body}

Empirical observations do suggest that the bodies of heart-beating, braindead donors continue to exhibit mitochondrially integrated, emergent properties of the "organism as a whole." For instance, Shewmon notes that the best cardiac donors are those "with intrinsic somatic integration not deriving from the brain." ${ }^{\prime 84}$ Shewmon illustrates this concept with two examples, breathing and nutrition, both of which integrate the body through biochemical processes. ${ }^{185}$ In the first example, Shewmon specifically mentions the mitochondrial use of oxygen in chemical respiration as an illustration of a somatically integrating function not deriving from the brain. This process integrates by providing the entire body with vital fuel, i.e., ATP. Yet overall, "somatic integration not deriving from the brain" appears a fitting description of the bodily integration that functioning mitochondria impose even more broadly by maintaining energetically functional, co-operating body tissues.

As this paper has explored in some depth, mitochondrial functioning appears to be responsible for many fundamental integrating functions of whole organisms. This seems to support Shewmon's claim that "[i]ntegrative unity is not a top-down imposition from a 'central integrator' on an otherwise unintegrated collection of organs." ${ }^{186}$ In contrast, Korein and Machado, citing previous works by Machado, claim that "consciousness ... is the most integrative function of the [human] body." "Even if that were so, there is evidence connecting mitochondrial malfunction to disorders of consciousness and physical dysfunction, specifically Alzheimer's and Parkinson's disease. ${ }^{188}$ Further contradicting Korein and Machado, when consciousness fails permanently, mitochondria in the bodies of brain-dead donors can still remain viable, allowing body systems to function (with breathing support) and permitting successful transplants. This suggests that consciousness is a less integrating force in the body than is mitochondrial function.

${ }^{184}$ Shewmon, “Critical Re-evaluation”, supra note 6 at 139.

${ }^{185}$ Ibid at 138.

${ }^{186}$ Ibid at 140 [emphasis in original].

187 Supra note 82 at 9.

188 Dong-Hyung Cho, Tomohiro Nakamura \& Stuart A Lipton, "Mitochondrial Dynamics in Cell Death and Neurodegeneration" (2010) 67:20 Cell Mol Life Sci 3435 at $3435,3441-42$. 
Shewmon's claim regarding superior cardiac donors is also consistent with the observations of Lane that successful transplantation appears to require viable mitochondria in donor organs. ${ }^{189}$ Taken together, these observations suggest that viable mitochondria exist in the bodies of ventilated, braindead donors who donate successful transplants. Yet the existence of viable mitochondria - mitochondria still capable of using oxygen, producing energy, and maintaining co-operating tissues ${ }^{190}$ - in a ventilated, brain-dead body contradicts the 2008 President's Council's analysis that such bodies lack a "needful openness" and cannot engage in "commerce with the world." This contradiction suggests a need for further research on bodily death and brain death, informed by a mitochondrial perspective.

Among brain-death scholars, Shewmon comes closest to arguing for a mitochondrial explanation of life's somatic integration ${ }^{191}$ and its loss in death, although he does so without discussing mitochondrial viability in much depth. ${ }^{192} \mathrm{He}$ observes, "[A] sine qua non of the opposition to entropy is energy, generated by [mitochondrial] chemical respiration, and a sine qua non of somatic integration is the circulation of [oxygenated] blood." ${ }^{193}$ Nota-

189 Empirically, following kidney transplant, “[m]itochondrial function in those first few minutes [after transplantation] foretold the outcome, perhaps weeks later - if the mitochondria failed in the first few minutes, the [transplant] inexorably failed": Lane, Power, supra note 90 at 314. To prevent organ rejection, a mitochondrial pore-protecting drug (cyclosporine A) is taken by transplant recipients: Hokanson, Mercier \& Brooks, supra note 178 at 1848 . These observations indicate a correlation between mitochondrial viability and transplant success.

${ }^{190}$ President's Council, supra note 11 at 64.

${ }^{191}$ Shewmon summarizes that 'some [claimed] key 'integrative functions,' if understood as brain-mediated, are not somatically integrating, and if understood as somatically integrating, are not brain-mediated": Shewmon, "Critical Reevaluation", supra note 6 at 138 [emphasis in original]. He cites cellular respiration as a chemical function of mitochondria as an illustration of this point: ibid.

192 Shewmon's meta-analysis also noted a possible positive relationship between a very young age at the time of the declaration of brain death and a longer period before the occurrence of spontaneous cardiac cessation on ventilator support: ibid at 135. Since younger patients will generally have fewer acquired mtDNA mutations, tissue functionality unimpeded by the effects of aging may be a possible explanation for his observation.

${ }^{193}$ Ibid at 142 [emphasis in original]. 
bly, he too describes human death as a somatic (i.e., body-centred) process, involving:

a critical degree of molecular-level damage ... throughout the body, beyond a thermodynamical "point of no return." The body's intrinsic tendency to active, anti-entropic ... selfmaintenance ... is irretrievably lost, so that physico-chemical processes now follow the path of increasing entropy characteristic of inanimate things (i.e., decay). [Death] does not require supracritical damage of every single cell in the body, but rather supracritical damage of enough cells of enough different types that the body as a whole loses its intrinsic ability to counteract entropy. ${ }^{194}$

He continues, "A clinical test for the 'point of no return' is therefore sustained cessation of circulation of oxygenated blood ... [U]nder ordinary circumstances ... an educated guess is that twenty to thirty minutes [of cessation] probably suffice to surpass 'the point of no return.,",195

While Shewmon did not explain his choice of duration, it is consistent with the 20-to-30-minute period of ischemia noted earlier, after which heart muscle may be permanently damaged, ${ }^{196}$ causing irreversible injury to the heart's mitochondria-rich cells and leaving an insufficient number of functional heart cells able to synchronously pump blood. In a later paper, he nuanced this time estimate, noting that in actuality it will be highly dependent on ambient temperature. ${ }^{197}$ Human death, based on a mitochondrial mechanism, does appear to involve a thermodynamic no-return point at which many mitochondria, irreversibly damaged by lengthy hypoxia, trigger enzymatic cell destruction. This would produce the widespread "supracritical" damage Shewmon described as occurring as a body loses its battle with entropy. Consistent with a mitochondrial mechanism for death, Shewmon argues that "[n]either spontaneous heartbeat nor breathing through the lungs is

\footnotetext{
${ }^{194}$ Ibid at 141-42 [emphasis in original].

195 Ibid at 142.

${ }^{196}$ Kumar, Cotran \& Robbins, supra note 119 at 6.

197 Shewmon, "Elephant", supra note 2 at 284-85.
} 
essential for life (as cardiopulmonary bypass machines effectively prove), but circulation and [mitochondrial] chemical respiration are."198

Despite the apparent similarity between Shewmon's reasoning and the views of this paper, his more recent publications reveal his perspective as grounded somewhat differently. Shewmon argues that a human being is a hybrid of a physical organism with a psychospiritual human mind, the latter being irreducible to the functions of the human brain. Quoting Pope John Paul II, he suggests that biophysical death (which he terms "deanimation") is:

a single event ... result[ing] from the separation of the lifeprinciple (or soul) from the corporeal reality of the person ... an event which no scientific technique or empirical method can identify directly [but after which] ... certain biological signs inevitably follow. ${ }^{199}$

Nevertheless, his sufficient and necessary criterion for the occurrence of biophysical death - "the irreversible cessation of the anti-entropic exchange of substances with the environment" 200 - again sounds evocative of a mitochondrial basis for biophysical death.

In contrast, as noted earlier, this paper adopts the perspective that the life and death of a human being are biological phenomena affecting the body, one aspect of whose functioning is the human mind. According to this view, then, death of the organism or body will automatically bring about death of the mind. Specifically, this paper has argued that, based on a mitochondrial mechanism, death of the organism occurs when the whole body undergoes hypoxia for a period sufficient to destroy most of the body's mitochondrial populations, resulting in a loss of energy supply and the associated emergent properties of the whole body (including the brain). In turn, loss of the brain's functional mitochondria causes the collapse of the epiphenomenon (or emer-

\footnotetext{
${ }^{198}$ Shewmon, "Critical Re-evaluation”, supra note 6 at 142 [emphasis in original].

199 Shewmon, "Elephant”, supra note 2 at 283, citing Pope John Paul II, “Address of the Holy Father John Paul II to the 18th International Congress of the Transplantation Society" (Speech delivered 29 August 2000), online: The Holy See <www.vatican.va/holy_father/john_paul_ii/speeches/2000/jul-sep/documents/ hf_jp-ii_spe_20000829_transplants_en.html> [emphasis in original].

${ }^{200}$ Shewmon, "Elephant", supra note 2 at 281.
} 
gent property) of the human mind. However, if hypoxia persists only long enough to cause destruction of the brain alone (which depends more heavily on mitochondrial energy supplies), mental emergent properties such as consciousness will vanish, while other tissues in the rest of the body that are less heavily energy-dependent (e.g., the heart) may continue to function, continuing to produce physical emergent properties of a complex body system, as Shewmon's meta-analysis observed.

How does life-support technology affect the picture? To a mitochondrion, it seems immaterial whether blood circulation is natural or artificial. ${ }^{201}$ As long as oxygenation and blood circulation continue by some means, mitochondrial energy production and entropy resistance can continue, avoiding widespread enzymatic cell destruction. With mechanized support, the mitochondria in a brain-dead body can remain viable, at least until factors such as systemic infection intervene. If populations of viable mitochondria - permitting whole-organism emergent functions and systemic integration - are what distinguish living from dead organisms, then we should consider as "living" a brain-dead patient whose breathing is supported, permitting a cardiac pulse to be generated by its heart cells and thereby allowing circulating, oxygenated blood to sustain the body's mitochondria sufficiently that the body can resist entropy. This is what Shewmon's study of ventilated, brain-dead patients appeared to observe.

\section{Addressing the Lack of Equivalence between Brain Death and Death of the Human "Organism as a Whole"}

While some argue that "death is best understood as an event and not a process, $" 202$ this appears inconsistent with the fact that hypoxia leads to tissue destruction at different rates in various tissues. The mitochondrial view correctly predicts that the first tissues affected by a loss of oxygenated blood are high-energy tissues such as neural tissues, resulting in the disappearance of energy-consumptive processes such as consciousness and the rapid onset of brain damage. More resistant tissues, such as leg muscle or glia, may remain viable longer than neurons or heart tissues, but eventually all will succumb to oxygen deprivation and necrosis. Thus it appears more likely that, as Bryan

201 "Natural" circulation uses heart and lung tissue, human or non-human, as in xenotransplantation. "Artificial" circulation of blood can be accomplished by an artificial heart or heart-lung bypass machine.

${ }^{202}$ Bernat, "Whole-Brain Defense", supra note 5 at 15. 
Jennett argues, "[d]eath is a process rather than an event" 203 - that is, a biological continuum of lost functions. ${ }^{204}$

Nevertheless, to facilitate social and legal necessities, it seems essential that death continue to be treated as a discrete event or "moment" rather than as a process, in order to enable important social processes such as the settling of estates and harvesting of donor tissues to continue without undue delay. Bearing societal needs in mind, how should we proceed? That is, if - as argued in this paper - mitochondrial viability provides a better explanation for the biological process of death than past scholarship has provided (which, admittedly, some may hotly dispute), are changes needed to the status quo regarding our treatment of death, in light of this new understanding?

One point requiring clarification is that accepting a mitochondrial mechanism for biological death does not inevitably mean that we would have to maintain brain-dead patients on ventilators, possibly for decades, while awaiting the expiry of all of the body's mitochondrial populations. First, few people seem likely to desire decades of life support for themselves or their loved ones, especially those patients who identify more strongly with their mental personhood characteristics than with their bodies. Advance directives allow life support to be withdrawn at a chosen point prior to death, and currently many PVS patients (who, by definition, are not "brain dead") have life support withdrawn well before death would occur "naturally." These observations provide precedent for the early removal of life support in cases where a patient's bodily mitochondrial populations still persist.

More importantly for both patients and families wishing to rely on life support and those who do not, it has always been customary, for purposes of social practicality, to set particular criteria for when human legal death is deemed to have occurred. This is done by physicians drawing a line - i.e., selecting legal criteria of death - at a point along the biological "dying continuum" of functional losses. The line-drawing process is intimately connected with the setting of specific tests, which are usually based on macroscopic,

${ }^{203}$ Bryan Jennett, “Brain Death” (1981) 53:11 Br J Anaesth 1111 at 1111.

${ }^{204}$ Death may be a continuum of body cooling, rigor mortis, dependent lividity, putrefaction, and, after centuries, mineralization of bony remains: Charles M Culver \& Bernard Gert, "The Definition and Criterion of Death" in Thomas A Mappes and David DeGrazia, eds, Biomedical Ethics, 6th ed (Toronto: McGraw Hill, 2006) 312 at 313. 
externally ascertainable signs (e.g., a heartbeat, breathing reflexes) that can be assessed non-invasively, without harming the patient. As mitochondrial populations appear to expire at different rates in different tissues, if we use mitochondrial expiry as a legal criterion of death, this would require that we specify which tissue(s) are to be tested. Even then, mitochondrial viability cannot provide a useful test that is non-invasive and externally ascertainable: the very act of sampling will destroy mitochondria by exposing the sample tissues to ischemia. Thus, even with a mitochondrial mechanism for biological death, we will require, for practicality's sake, macroscopic legal criteria of death that can be easily tested.

Therefore, the real issue to be decided is the choice of the legal criterion (or criteria) we ought to use for death, in light of our knowledge regarding mitochondrial contributions to life. More particularly, if we agree that, based on a mitochondrial mechanism, brain death and death of the "organism as a whole" are not actually biologically equivalent - contradicting many scholarly claims made since 1968 - should we continue to use brain death or abandon it as a legal criterion of death?

To some, one option might be a "business as usual" approach, ignoring what mitochondrial science tells us and continuing to state that brain death is identical to bodily death. Yet this seems less than ideal, since this approach maintaining increasingly convoluted and contradictory explanations of brain death $^{205}$ - may be creating cognitive dissonance and moral distress among health care workers as to whether they should treat brain-dead patients as

${ }^{205}$ As noted earlier, the President's Council report sets three minimal criteria for living organisms: openness to environmental stimuli, a felt drive to act on the environment to meet some need, and a capacity to act on its own behalf to meet that need: supra note 11 at 61 . Yet its application of these criteria is error-prone and contradictory. For instance, to distinguish PVS patients from the dead (ibid), the Council cites several characteristics not actually possessed by PVS patients: see text at notes 68-75, supra. The Council also seems to imply initially that the intake of both "food and water" and "even more basically" air may both be sufficient evidence of a living organism's capacity for action: ibid at 62. But by the end of the paragraph and subsequently (e.g., at 63-65, and implicitly at 90-91), only spontaneous breathing (which brain-dead bodies do not display) is cited as potential evidence of capacity and appetitive drive to act. The reasons for not considering water and nutrient intake (which brain-dead bodies do exhibit) as evidence of life are not clarified. 
"really dead." ${ }^{206}$ Surveys indicate that $71 \%$ of Canadians surveyed also do not understand the term "brain death" to be equivalent to death in the commonly understood sense. ${ }^{207}$ Conceivably, low organ donor rates ${ }^{208}$ may be connected with this public skepticism about brain death. ${ }^{209}$ Furthermore, it seems that continuing to provide outdated, scientifically unsupported information and to omit salient details about brain death is inconsistent with legal requirements for informed consent, a basic tenet of modern health care. This may render any consent given invalid, which would make organ harvesting a battery on the patient (as discussed in greater detail later in this section), regardless of the patient's desire during life to donate his or her organs.

A new approach to death therefore seems highly advisable, an approach whose guiding principle is that we not mislead patients by omission or otherwise, and thus avoid abusing their trust and invalidating their consent. It is no answer to argue that the accuracy of the information provided to patients about death matters little, on the grounds that existing patient choices - e.g., a patient's advance directive requesting that life support be withdrawn long before death, upon the loss of personhood features - may in practice truncate some patients' lifespans. Exercise of such choices is a separate legal matter, one that does not render accuracy in discussing biological death any less a requirement generally, simply because some patients may choose lifesupport withdrawal early in the dying process. Death is a highly emotional issue for most people and declaration of death, according to whatever crite-

${ }^{206}$ Robert D Truog, "Brain Death - Too Flawed to Endure, Too Ingrained to Abandon" (2007) 35:2 JL Med \& Ethics 273 at 274-75, 277.

207 Canadian Council for Donation and Transplantation, Public Awareness and Attitudes to Organ and Tissue Transplantation Including Donation after Cardiac Death: Final Report, December 2005, online: CCDT <www.organsandtissues.ca/ s/wp-content/uploads/2011/11/Public_Survey_Final_Report.pdf> at 8 .

${ }^{208}$ While $96 \%$ of the public and $99 \%$ of medical professionals "approve of" organ donation after death, only $55 \%$ of the public and $68 \%$ of medical professionals, respectively, have decided to donate their own organs: see ibid at 7; Canadian Council for Donation and Transplantation, Health Professional Awareness and Attitudes on Organ and Tissue Donation and Transplantation Including Donation after Cardiocirculatory Death, August 2006, online: CCDT <www.organsandtissues.ca/s/wp-content/uploads/2011/11/Survey-HealthProf.pdf $>$ at 14-15.

${ }^{209}$ See Shewmon, “Critical Re-evaluation”, supra note 6 at 129-30. 
ria, signifies a major withdrawal of legal rights. Given the important social and legal implications that flow from death declaration, a "casual" approach to providing patients with information about the nature of biological death and how it may diverge from those criteria - cannot be regarded as acceptable.

Also, while organ donors and those using advance directives can exercise some choice by requesting that their deaths occur relatively early, for everyone else there is currently no option available as to when death will be declared. There has been no societal decision in Canada (e.g., through Parliament) regarding the point in the dying continuum at which death should be declared. Adoption of brain death as a second legal death criterion was not a choice made by society as a whole, but was imposed by members of the medical profession in 1968. Although the 1981 Law Reform Commission of Canada urged that a legislative (and therefore democratic and societal) definition of death be adopted, this recommendation was never acted upon. Thus, for most Canadians, the current arrangements and information regarding brain death cannot be said to reflect socially agreed-upon choices.

Approaching the issue afresh suggests that, ideally, death should be declared only when a significant proportion of the body's mitochondrial populations has been destroyed. Given the current lack of satisfactory means to assess this point in a patient using external signals, ${ }^{210}$ as an alternative we might concede the inequality of brain death and bodily death, and abandon brain death as a legal criterion, retaining only the time-honoured cardiopulmonary criterion of death. Using a cardiopulmonary criterion provides a more certain indication that the body's mitochondrial populations will have succumbed to the effects of hypoxia. It bears noting, however, that the cardiopulmonary criterion is also an imperfect estimate of when death occurs, as it also reflects a line drawn at an easily testable point within the "dying continuum." Mitochondria in the body do not die immediately upon cardiopulmonary arrest (nor for some time if artificial oxygenation and recirculation of blood continue). Therefore - like brain death - the cardiopulmonary death criterion indicates only approximately when the death of the entire organism, in the absolute or commonly understood sense, occurs.

210 To assess mitochondrial viability in a donor organ, Lane used near infrared and another unspecified form of spectroscopy: Lane, Power, supra note 90 at 312-13. This technique cannot be used non-invasively, however. 
Using only a cardiopulmonary criterion also poses disadvantages. Due to the fact that individuals declared dead using a cardiopulmonary criterion undergo a damaging period of warm ischemia, transplants from heart-beating, brain-dead donors are preferred. ${ }^{211}$ Transplants from donors with a heartbeat can be harvested earlier and are more successful than those obtained via a cardiopulmonary criterion. Abandoning brain death would therefore substantially decrease current organ availability and successful transplantation rates, which are already inadequate to meet present needs. ${ }^{212}$ More patients would die awaiting transplants, and the health care costs of providing other therapies in place of transplants (where such therapies are possible) might in-

211 Transplant success increases with earlier organ harvesting and better hypoxia protection. Organs from brain-dead bodies experience less hypoxic exposure of mitochondria than those in bodies that have undergone cardiopulmonary death, as noted by the President's Council:

If surgeons wait for the more traditional signs of death [e.g., a cessation of cardiopulmonary activity], the organs endure a period of "warm ischemia" during which they are deprived of nourishing blood and oxygen. While it is possible to procure some organs under these circumstances, concerns about ischemic damage make the heart-beating, "brain-dead" donor the preferred source of organs [supra note 11 at 8].

A 1977 study also observed that "if the pronouncement of death were delayed until the heart stopped beating, the organs underwent so much deterioration that a successful transplant was jeopardized": see NINCDS, supra note 32 at 982 . The later time of cardiopulmonary declaration may mean that organs will be harvested later from patients, exposing organs to a longer period of deterioration due to infection, drug side effects, etc., in addition to warm ischemia. Before 2006, Canadian organs from deceased donors were only obtained from brain-dead patients. However, by 2009, four Canadian provinces (British Columbia, Ontario, Quebec, and Nova Scotia) had begun to harvest some organs after "cardiocirculatory" death (i.e., death declared based on cardiac rather than neurological criteria), although these represented fewer than 10\% of donations: see Canadian Institute for Health Information, "Organ Donor Activity in Canada, 1999 to 2008" (22 December 2009), online: CIHI <https://secure.cihi.ca/free_products/CORR_AiB_ EN_20091222_rev20100106.pdf $>$ at 1 .

212 See Canadian Blood Services, Call to Action: A Strategic Plan to Improve Organ and Tissue Donation and Transplantation Performance for Canadians, online: CBS <www.organsandtissues.ca/s/wp-content/uploads/2012/06/OTDT-INDXfinal-C2A.pdf $>$ (" $[t]$ he acute shortage of organs means provinces and programs must share organs to minimize the number of deaths of critically ill patients on waitlists" at 77). 
crease. ${ }^{213}$ Therefore, from a utilitarian perspective, reverting to a solely cardiopulmonary criterion is not ideal, although it could be considered.

Alternatively, to protect organ transplantation, we could acknowledge that brain death is not equivalent to bodily death, but abandon the DDR, ${ }^{214}$ under which organs must only be obtained from patients considered "dead." If brain death does not necessarily indicate bodily death based on mitochondrial function, then, biologically speaking, a brain-dead, heart-beating patient can only be said to be "dying," rather than fully dead, despite having been declared legally dead. Abandoning the DDR would permit organ harvesting from brain-dead donors during the period that their bodies are legally, but not biologically, dead.

While this could preserve organ donation, some may argue that, according to Kant's categorical imperative, such brain-dead individuals will thereby be treated unethically, as means rather than as ends in and of themselves. Yet it may be countered that if we agree to accept brain death as a legal criterion but abandon the DDR, then for a human being who autonomously consented during life to organ harvesting, brain death could be held to mark the point where that patient as a legal person disappears. Under this account, Kant's categorical imperative might not be violated by the use of the mitochondrially still-living body of a brain-dead patient as a "means" (in ways to which the patient has consented). Yet admittedly, others may strongly disagree, seeing the removal of organs from a consenting donor's "still-living" body as inherently unethical and a crime. ${ }^{215}$ Even if it is acceptable, it will only be so if an important legal consideration - valid donor consent - is satisfied, mean-

213 The cost effects are unclear, but those associated with end-stage kidney disease, at least, might rise due to the potential that costly dialysis would have to be provided longer and to more patients to address a decline in the availability of kidneys for transplant.

${ }^{214}$ Truog, supra note 206 at 279-80.

215 See Christian Munthe, "Why I'm Sceptical to the Idea of Harvesting Donor Organs from Living People" (23 March 2013), Philosophical Comment (blog), online: PC <www.philosophicalcomment.blogspot.ca/2013/03/why-im-sceptical-to-idea-ofharvesting.html $>$ ("[t] he problem is, ... if we are to take away the DDR - we would have to say that intentionally cutting up a living person so that he or she dies is sometimes not a crime"). 
ing that the consent is voluntary and informed. Thus, the information provided to patients on brain death and organ donation must be accurate.

A final option might be to acknowledge that brain death is not death of the body or organism, and to explicitly declare brain death as a "legal fiction" - either a common law or statutory rule that claims as legally "true" a state of affairs that may not be literally accurate. One example is "legal blindness," in which a person may not be completely blind, but is treated from a legal standpoint as if he or she were totally blind; the same social benefits thereby flow to the partially sighted as to the totally blind. ${ }^{216}$ This uses the term "blind" "in a biologically incorrect way for its socially beneficial purpose." ${ }^{217}$ Unlike in legal blindness, the benefit of a legal fiction regarding brain death would flow mainly to third parties (e.g., organ recipients), rather than to the individual who is the subject of the legal fiction.

Legal fictions have been used to deny some human beings legal recognition. ${ }^{218}$ For instance, via a legal fiction applied to cases of missing persons, legal recognition can be removed from an individual not known to be biologically dead, but presumed dead after a number of years' absence. That is, it is understood that a missing person might still be biologically alive, but that he or she may be unable or unwilling to be found. The legal fiction of the person's death permits heirs and creditors to dispose of the missing person's estate without fear of legal repercussions, should the "deceased" reappear.

Some might argue that in a missing persons case, we do not know if the missing individual is dead or alive, whereas after applying a medical test for death, we would know that the individual is dead, making a legal fiction unnecessary. But this ignores the fact that our "knowledge" about someone's death - an inherently subjective experience of another individual - is necessarily limited to what we can ascertain externally about that individual's state, based on information obtained from the tests for death. These tests assess whether the individual's functional losses meet the legal line (criterion)

216 The analogy between a legal fiction for death and the legal fiction for visual impairment was proposed in Robert M Taylor, "Reexamining the Definition and Criteria of Death" (1997) 17:3 Semin Neurol 265 at 269.

${ }^{217}$ Bernat, "Whole-Brain Optimum", supra note 23 at 41 (referring to the argument in Taylor, supra note 216).

${ }^{218}$ See Hughes, supra note 173 at 82-83. 
drawn in the biological "dying continuum" from birth to final decay as an approximation of death that facilitates social decisions. Our knowledge of a patient's real experience is only as good as our tests for death, tests which are always somewhat deficient, insofar as they are both external observations of the patient's subjective reality and approximations. Thus, we do not know, based on test results, that an individual who tests as brain-dead is in fact "dead" according to the patient's own subjective experience.

This uncertainty is compounded by the use of improper or inadequate tests for death, as discussed in an earlier paper published by the present author. $^{219}$ It appears likely, according to the best scientific information, that use of these tests has sometimes led to false declarations of brain death in cases of reversible conditions created by confounding variables, e.g., barbiturate intoxication. However, once ventilator support is withdrawn after a positive brain-death test determination, we do know from a mitochondrial perspective that the patient will shortly become dead, since hypoxia will rapidly destroy the body's mitochondria within some tens of minutes at room temperature, as noted earlier.

It seems, based on existing examples, that the public is willing to accept various legal fictions that permit extension of benefits to society's more vulnerable members or that prevent indefinite disruption of important social processes. Similarly, brain death could be acknowledged as a legal fiction permitting a patient to donate needed organs when permanent loss of brain function has occurred. This fiction would recognize that, although the body of the affected individual is not biologically dead, the patient's cortex and brain stem are so severely damaged that they are extremely unlikely ever to recover functionality, even while the heart and body tissues may still be mitochondrially functional. This fiction would benefit not only organ recipients, but also those wishing to leave a "living legacy" through organ donation. Publicly acknowledging the lack of equivalence of brain death and bodily death might also increase public trust in, and better understanding of, the diagnosis of brain death. Dropping the claim of equivalence might also foster greater trust in organ donation, with gains in donor numbers being a possible result.

219 Jacquelyn Shaw, "A Death-Defying Leap: Section 7 Charter Implications of the Canadian Council for Donation and Transplantation's Guidelines for the Neurological Determination of Death" (2012) 6:1 McGill JL \& Health 41. 
However, others may disagree. Some may fear that abandoning the claim of brain death and bodily death equivalence may cause more patients to refuse organ donation. Several considerations have relevance here. First, as noted above, some patients value and strongly identify with their mental personhood characteristics and so would not wish to continue existence once personhood has vanished in a seemingly irreversible manner. Indeed, some already draw up advance directives reflecting this position. While not all hold this view, those who do appear highly unlikely to alter their views after being told that in brain death, the mitochondria of much of the body may persist, a consideration having no bearing on mental personhood characteristics. Thus, for patients who primarily value personhood, this change in information should have little effect on a choice to donate.

But not all patients share a view prioritizing mental personhood over all else and, therefore, some might refuse to donate organs if more accurate information is provided. Yet it must be remembered that this is a patient's legal right in a health care system that prioritizes patient autonomy over physician paternalism. In Canada, the "therapeutic privilege exception" to fully informing patients is now very narrow where it exists at all, and it is not available to prevent patients from refusing to consent to a physician's preferred choice of procedure. ${ }^{220}$ Outside the therapeutic privilege exception, it is a legal requirement in health care to supply accurate information; what patients may do with that information is never an acceptable basis for denying, downplaying, or distorting it.

${ }^{220}$ In Canada, based on the Reibl v Hughes standard, a patient (or his/her proxy) must be informed of all of the material risks of which an objective, reasonable patient would want to know, in addition to more specialized risks that the particular patient may subjectively value: Reibl v Hughes, [1980] 2 SCR 880 at 899-900, 114 DLR (3d) 1. An exception proposed by Laskin CJC in that case is "therapeutic privilege" (ibid), which in theory could permit a physician to withhold or downplay negative information that, in his/her opinion, may have a negative or countertherapeutic effect on a vulnerable (e.g., young or suicidal) patient's outcome. However, jurisprudence and doctrinal writing suggest that "[i]f available at all, [therapeutic privilege] has a very limited scope" and would stand at best "on narrow and shaky grounds": Jocelyn Downie, Timothy Caulfield \& Colleen M Flood, Canadian Health Law and Policy, 6th ed (Markham, Ont: LexisNexis, 2011) at 173-74. Thus, therapeutic privilege could not be used to justify providing inadequate information about brain death to patients, simply out of a concern that betterinformed patients will refuse to consent to organ donation. 
The reason for this is that, like any medical procedure performed on a patient, organ harvesting will constitute battery if it turns out that valid (i.e., voluntary, informed, competent) consent for the procedure was not obtained. Specifically, in the case of surgery, a battery occurs "where there is no consent to the surgery at all, where the terms of the consent have been clearly exceeded, or where the nature and character of the surgery have been misrepresented." 221 The last possibility exists where a patient - or family member - has been led to consent only to surgical organ harvesting from a body which is no longer living, biologically speaking, and not one which still possesses an independent pulse and living tissues. As Shewmon observes,

[w] hen they read the phrase "after my death" [on an organ donor card or other authorization document], many imagine a pulseless corpse and might be horrified to learn that it really means "after I become comatose and apneic but all my other organs are working fine," and that "I will be eviscerated while still pink and warm, with my heart still spontaneously beating and blood circulating.",222

More recently, an editorial in the journal Nature suggested that "[i]deally, the [US] law should be changed to describe more accurately and honestly the way that death is determined in clinical practice.... The time has come for a serious discussion on redrafting laws that push doctors towards a form of deceit." 223 Other than the fact that organ harvesting is performed on an individual who has been declared dead rather than on a still-living patient, the circumstances of organ harvesting do not appear to differ in any way from other medical procedures for which informed consent is required. The legal need for informed consent to medical care stems from respect for the patient's physical body and for his or her competent wishes as to what may be done to it; as in other areas of the law, such as wills and estates, the requirement to respect the wishes of the deceased should not end with declaration of the patient's death, but should survive it.

${ }^{221}$ Philip H Osborne, The Law of Torts, 4th ed (Toronto: Irwin Law, 2011) at 283 [emphasis added].

${ }^{222}$ Shewmon, "Critical Re-evaluation”, supra note 6 at 144.

223 "Delimiting Death: Procuring Organs for Transplant Demands a Realistic Definition of Life's End", Editorial (2009) 461:7264 Nature 570 at 570. 
For those patients and families willing to give informed consent, if we choose to retain brain death as a legal fiction, then it is suggested that a whole-brain criterion be selected for neurological death declaration. Clearly, some might disagree with this choice, including transhumanist author James Hughes, who believes that "[t]his century will begin to see a shift toward consciousness and [mental] personhood-centered ethics as a means of dealing ... with brain death." 224 In a patient affected by hypoxia, it seems likely that the high-energy neural tissues of the cortex will likely be among the first to die, due to their significant mitochondrial energy needs, supporting the view that the patient's mental personhood characteristics may be lost. Yet societal values suggest that we not adopt the "neocortical" criterion of death that Hughes mentions, since neocortical destruction is the diagnostic picture presented by the case of PVS patients, who may often breathe independently, requiring no ventilator assistance. The presence of these features is likely to trigger a strongly negative societal reaction to treating these still-breathing, heart-beating patients as a source of organs or as ready for burial. Attesting to this, no country to date has adopted a neocortical criterion. Moreover, some patients diagnosed as being in a PVS have later reawakened, even decades after their initial diagnosis, ${ }^{225}$ and recent studies have shown high levels of PVS misdiagnosis (i.e., the patients in fact suffered a less serious impairment than PVS). ${ }^{226}$ These factors suggest that there is too much we do not yet understand about these disorders to risk disposing of PVS patients as "dead" through the adoption of a personhood-centred, neocortical criterion of death.

A brain stem criterion of death also appears unwise. As noted above, the brain stem is more anoxia-resistant than the cortex,${ }^{227}$ probably due to relative differences in neural composition and mitochondrial energy needs. Thus, in injuries caused by systemic oxygen-deprivation, it might be expected that death of the hardier brain stem will predict a mitochondrially dead cortex.

${ }^{224}$ Hughes, supra note 173 at 85.

${ }^{225}$ See Peter McCullagh, Conscious in a Vegetative State? A Critique of the PVS Concept (New York: Kluwer Academic Publishers, 2004) at 163-70.

${ }^{226}$ In one study, $43 \%$ of PVS patients were misdiagnosed: see Keith Andrews et al, "Misdiagnosis of the Vegetative State: Retrospective Study in a Rehabilitation Unit” (1996) 313:7048 Brit Med J 13, cited in McCullagh, supra note 225 at 150.

${ }^{227}$ See Law Reform Commission, supra note 43 at 13-14. 
However, as alluded to earlier, this is not necessarily so. Brain stem damage can occur via means other than systemic anoxia or hypoxia, e.g., through isolated brain stem injury. As acknowledged by Bernat in rejecting a brain stem criterion, an isolated brain stem injury could leave the cortex unimpaired, permitting retention of a patient's capacity for residual awareness, possibly including pain awareness. ${ }^{228}$ Consequently, neither the higher cortical criterion nor the brain stem criterion seems socially acceptable for approximating the time of death. It is concerning, therefore, to note Canada's recent adoption of the brain stem criterion and the possibility (suggested by some authors) that the US may follow suit in the future. ${ }^{229}$

Thus, if we employ brain death as a legal fiction and legal death criterion, the least objectionable version of the neurological criterion of death seemingly remains a whole-brain criterion, which, if assessed carefully using appropriately set tests, will provide a reasonably high degree of assurance as to whether both the potential for conscious awareness (the cortex) and the capacity for wakefulness (the brain stem) have been destroyed. Although the mitochondria of the brain stem and cortex may no longer be viable once whole-brain death has occurred, the mitochondria within the body's tissues may still function with ventilator support, due to the different energy needs of these various tissues; thus, effective transplantation of organs and tissues would still be possible.

${ }^{228}$ Bernat, "Whole-Brain Optimum", supra note 23 at 39. See also PJ Young \& BF Matta, "Anaesthesia for Organ Donation in the Brainstem Dead - Why Bother?" (2000) 55:2 Anaesthesia 105 at 105-06. While these anaesthetist authors note (at 106) that it is "probable" that brain-stem-dead donors have no consciousness during organ harvesting, they observe that this is not certain and that there exist signs, e.g., significant blood pressure and heart rate increases, that "demand caution before assuming that anaesthesia is not required" in the operation: ibid at 105 . They conclude that "[f]aced with the knowledge of the persistence of higher brain and spinal function in some donors, ... sedation and analgesia [i.e. pain reliever] should be given with muscle relaxation for organ donation": ibid at 106 [emphasis added].

229 This possibility arises from the US choice of "apneic coma" as the conceptual essence of neurological death criterion, since this may be produced by either brain stem or whole-brain death: see Shewmon, "Brain Death Resuscitated", supra note 4 at 22. 


\section{Conclusion}

Humankind has long pondered death's enigmatic commonalities: its trans-species universality; its apparent inevitability and link with aging; its irreversibility; and its association with the loss of somatic integration, the loss of whole-organism emergent properties, and the onset of entropic decay. Earlier scholarship has not successfully explained all of these features. The lost viability of the body's mitochondrial populations appears to offer a coherent explanation of death. That is, death involves irreversible damage e.g., by prolonged hypoxia - to the body's mitochondria in vital tissues or in a sufficiently wide range of tissues, leading the mitochondria to trigger cell death en masse. On this view, once a critical number of mitochondria is destroyed by hypoxic damage or mutation, there is no longer sufficient energy to fuel anti-entropic life processes, and bodily disintegration becomes inevitable.

Unfortunately, no current means allow non-invasive testing of mitochondrial viability, suggesting that at present we should continue to use more approximate, externally testable death criteria, such as the cardiopulmonary and neurological criteria. However, to satisfy the legal requirements of informed consent for organ donation, any continued use of brain death must occur in the context of providing patients with fuller and more scientifically supported information about brain death. In future cases, consent will not be valid if the biological reality of brain death (the point when organ harvesting becomes legal) does not match patients' understanding of it, based on what they have been told; where the patients are misinformed, organ harvesting will potentially constitute a battery.

From a body-centred perspective on death, our complex relationship with mitochondria may account for some of death's more mysterious aspects: its intangible losses, its seeming inevitability, and our current inability to reverse it technologically. Ironically, this explanation means that human life, at all levels of sophistication, is utterly dependent on the viability of simple bacterial symbionts only very distantly related to human beings. The role of mitochondria in human life and death has been overlooked for over four decades in the legal and bioethical literature, which has focused instead on processes observable at the whole-organism level. These omissions are understandable given the complex relationship between mitochondria and host cells and the fact that the relationship has only quite recently - in the past 20 years - begun to be understood as the unique symbiosis that it is. 
Occam's razor suggests that the most "parsimonious" explanation of phenomena be adopted. ${ }^{230}$ The adoption of brain death predates the mainstream scientific acceptance of mitochondria as ancient bacteria, ${ }^{231}$ before which it was more "parsimonious" to view humans as monolithic, single organisms. This view requires modification. It is now widely accepted that mitochondria are descended from ancient bacteria; that they supply the vast proportion of the energy that eukaryotic organisms consume; that they are intricately and symbiotically engaged with host cells in directing cell death, bodily development, and aging; and that their dysfunction is increasingly linked to serious diseases. Thus, it may now be more parsimonious to view the human organism as a symbiotic, co-operative venture, rather than as a monolithic entity. ${ }^{232} \mathrm{~A}$ new paradigm appears to be emerging in medicine in which the central role of mitochondria in life, aging, and disease is explored,

${ }^{230}$ Also known as Ockham's razor or the "Law of Parsimoniousness," credited to medieval Friar William of Ockham, who stated in his writings, "Plurality must never be posited without necessity" ("Numquam ponenda est pluralitas sine necessitate"): William of Ockham, Sentences of Peter Lombard (1495). This rule urges choosing the hypothesis that makes the fewest assumptions, while still adequately explaining observed phenomena.

231 Although the endosymbiont theory of mitochondria as former bacteria was proposed in 1967, it was rejected by mainstream science until 1981: Lane, Power, supra note 90 at 14-16. Harman's mitochondrial theory of aging, supra note 159, emerged in 1972. Therefore the idea of a human-mitochondrial symbiosis would not have been part of mainstream science in 1968, when brain death was first adopted.

${ }^{232}$ Human cells may be likened to miniature ecosystems. As Lewis Thomas wrote,

[a] good case can be made for [human] nonexistence as entities. We are not made up, as we had always supposed, of successively enriched packets of our own parts. We are shared, rented, occupied. At the interior of our cells, driving them, ... are the mitochondria, and in a strict sense they are not ours. They turn out to be little separate creatures.... Without them, we would not move a muscle, ... [nor] think a thought [Lewis Thomas, The Lives of a Cell: Notes of a Biology Watcher (New York: Viking Press, 1974) at 3-4].

Yet "reductionist" human thinking may "prefer a top-down perspective," focused on the whole human organism and its emergent processes (e.g., consciousness), while ignoring less visible cellular or molecular activity: Lloyd, Rossi \& Roussel, supra note 118 at 5 . 
understood, and finally acknowledged. Accordingly, a new biological perspective on the criteria of legal death seems appropriate. ${ }^{233}$

Since 1968, mainstream medicine has maintained - despite evidence to the contrary - that in brain death, the body is dead (or will be within days), permitting organ harvesting under the DDR. Yet a mitochondrial mechanism for death implies that brain death is not equivalent to death, in the commonly understood bodily sense of that word. Other authors, such as Shewmon, have previously suggested this same conclusion, but without fully exploring the relevance of mitochondrial function. Based on a mitochondrial perspective, the lack of equivalence between brain death and bodily death may appear to threaten the DDR. Ultimately, however, recognizing the non-equivalence of brain death and bodily death need not necessitate abandoning brain death and, with it, organ donation. A simpler option may be to retain whole-brain death as a criterion of death, while acknowledging it as a biologically incorrect "legal fiction," much like legal blindness. This more frank approach may better assist patients needing transplants, as well as those wishing to donate organs, thereby creating opportunities to share the life-giving energy - and co-operative spirit - of an ancient symbiosis.

${ }^{233}$ See e.g. Michelakis, supra note 98 at 2431-34; Wallace, "Mitochondrial Paradigm”, supra note 90 at 393; Ryan L Parr \& Luis H Martin, "Mitochondrial and Nuclear Genomics and the Emergence of Personalized Medicine" (2012) 6:3 Hum Genomics 1 at 2. Conversely, in his analysis of death, Shewmon argues that a new integrating paradigm seems warranted, given the incompatibility of many individual observations regarding death: "Attempts to construct the entire 'death elephant' from all the disparate perspectives [of previous scholars] have been stymied by the apparent incompatibility between certain features, ... a sure sign that a fundamental paradigm shift is required": Shewmon, "Elephant", supra note 2 at 290. 